GRIPS Discussion Paper 19-32

\title{
Environmental Taxes and Productivity: Lessons from Canadian Manufacturing
}

\section{Akio Yamazaki}

February 2020

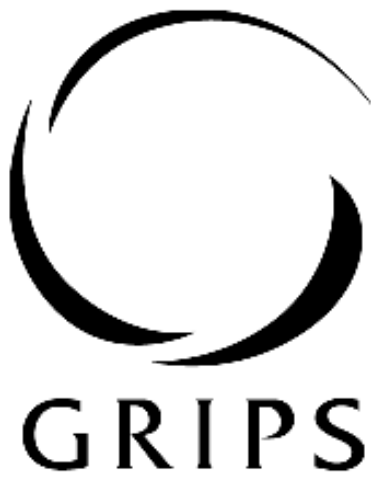

National Graduate institute FOR POLICY STUDIES

National Graduate Institute for Policy Studies 7-22-1 Roppongi, Minato-ku, Tokyo, Japan 106-8677 


\title{
Environmental Taxes and Productivity: Lessons from Canadian Manufacturing*
}

\author{
Akio Yamazaki ${ }^{\dagger}$ \\ National Graduate Institute for Policy Studies
}

Version: December, 2020

\begin{abstract}
This paper investigates how environmental taxes affect manufacturing productivity by examining British Columbia's revenue-neutral carbon tax. I develop a new hypothesis, the "Productivity Dividend Hypothesis," to show that environmental taxes can positively affect productivity by recycling tax revenues to reduce corporate income taxes. This revenue-recycling increases investment and could raise productivity more than environmental taxes lower productivity by diverting resources from production. I evaluate this hypothesis using detailed confidential plant-level data. I find that the carbon tax lowers productivity, although this is offset to some extent by the revenue-recycling. For some plants, the policy generates a net gain in productivity.
\end{abstract}

Key Words: Environmental tax; revenue-recycling; manufacturing; productivity

JEL Codes: D22, H23, L6, Q5

${ }^{*}$ I am very grateful to my advisors, Kenneth J. McKenzie, Stefan Staubli, and M. Scott Taylor for their great supervision and invaluable advice. I would also like to thank Stefan Staubli for helping me obtain the micro-level data. The paper also benefited from extensive discussions with Loretta Fung, Nouri Najjar, Nicolas Rivers, and Trevor Tombe. I also thank Mark Curtis, Carol McAusland, Kerry Smith, Tracy Snoddon, and seminar participants at many conferences, workshops, and universities during 2018-2019 for their very helpful comments. I acknowledge generous funding from Productivity Partnership (PP) and Smart Prosperity Institute (SPI), supported by the Social Sciences and Humanities Research Council of Canada. Views expressed in this paper do not necessarily reflect those of Statistics Canada, PP, or SPI. This paper has been screened to ensure that no confidential data are revealed. All remaining errors are my own.

${ }^{\dagger}$ Address: National Graduate Institute for Policy Studies, 7-22-1 Roppongi, Minato-ku, Tokyo, Japan 106-8677. Email: a-yamazaki@grips.ac.jp 


\section{Introduction}

Implementing environmental policy is a challenging task. Environmental benefits are difficult to quantify and may come at the cost of economic growth and jobs although this is uncertain. Among various policy instruments available, environmental taxes have recently gained popularity, especially in Europe, due to its ability to raise revenues. ${ }^{1}$ Such revenues are sometimes used to reduce the existing distortionary taxes, thereby stimulating economic growth. In the wake of the Paris Agreement, many more jurisdictions are considering some types of carbon pricing policy to reduce emissions. Policymakers then face a challenge in deciding how to use the revenues. To guide policymakers on this issue, this paper investigates how environmental taxes affect manufacturing productivity when the tax revenues are recycled. I answer this important question by examining the revenue-neutral carbon tax implemented by British Columbia in 2008.

Investigating the productivity effect on the manufacturing sector is important for three reasons. First, the manufacturing sector is still one of the largest sectors in the economy around the world. ${ }^{2}$ Second, the manufacturing sector plays an essential role in future innovation because its R\&D expenditure is large, and technological advancements in manufacturing positively affect the rest of the economy. Third, policymakers and the public worry that manufacturing firms would suffer greatly from additional costs imposed by the carbon tax because the manufacturing sector is both emission-intensive and trade-exposed.

British Columbia (BC) implemented a carbon tax on July 1st, 2008, applying it to the purchase of all fossil fuels for all consumers. It is the first and most comprehensive carbon pricing policy in North America. The policy provides unique features that one can take advantage of to clearly identify the productivity effect of the policy. First, the policy was implemented only five months after its announcement. This surprise and quick implementation gave no room for polluting plants to adjust their operations to minimize the tax burden prior to the implementation. Second, the tax rate was set at a relatively high rate, which provided strong incentives for plants to adjust operations to reduce their emissions. Third and most importantly, all of the tax revenue raised was returned back to the economy to keep the government revenue constant, i.e., a revenue-neutral policy. The revenues were used to reduce personal and corporate income taxes and provide lumpsum transfers to low-income households. In this paper, I particularly focus on the importance of this revenue-recycling via the reduction of corporate income taxes on productivity.

My empirical strategy is motivated by a simple model of the total factor productivity (TFP)

\footnotetext{
${ }^{1}$ See Bosquet (2000) for the list of European countries with different types of environmental taxes.

${ }^{2}$ For example in BC, manufacturing sector comprises 10 percent of the provincial GDP, and it is a major contributor to exports. In terms of jobs, 20 percent of jobs are in the manufacturing sector and their wages are 15 percent higher than the provincial average (Heartwell, 2012). In addition, 30 percent of the national GDP in China is from the manufacturing sector (see https://data.worldbank.org/indicator/NV.IND.MANF.ZS?locations=CN).
} 
residual. By incorporating abatement investment decisions into the model, I develop a new hypothesis to show that environmental taxes can positively affect productivity by recycling tax revenues to reduce corporate income taxes (CIT). The model shows that there are two distinct channels through which a revenue-neutral carbon tax affects the plant's productivity. First, the model predicts that taxing energy purchases diverts some productive resources away from production to regulatory compliance, lowering productivity. At the same time, it could induce more investment in abatement, enhancing productivity. The productivity effect of this "carbon tax effect" is determined by these two channels.

Second, recycling revenues from the carbon tax to lower the rate of the CIT positively affects productivity. This comes from the fact that this "revenue-recycling effect" ameliorates the distortionary nature of the CIT system, increasing the productivity-enhancing investments.

When this revenue-recycling effect raises productivity more than the carbon tax lowers productivity by diverting resources from production, a revenue-neutral carbon tax can lead to a net gain in productivity. I name this hypothesis the "Productivity Dividend Hypothesis" (PDH). Furthermore, if the revenue-neutral carbon tax also reduces emissions, it offers a double dividend. I name this the "Productivity Double Dividend (PDD) Hypothesis."

I evaluate the PDH using a unique detailed confidential plant-level data containing longitudinal information on the corporate income tax and manufacturing production. This detailed data allows me to separately identify the carbon tax and revenue-recycling effects on productivity. I identify both effects, not only by comparing plants in BC with plants in the rest of Canada (ROC) before and after the implementation of the carbon tax, but also by comparing plants based on plant characteristics that are directly related to each effect.

The carbon tax effect is estimated using the plant-level carbon tax expenditure intensity. Using the data on the fuel-specific energy expenditure, I calculated how much each plant paid for the carbon tax relative to its value-added. If high carbon tax expenditure intensive plants in BC experience a larger decline in productivity relative to low carbon tax expenditure intensive plants in $\mathrm{BC}$, this productivity decline can be interpreted as the effect of the carbon tax. The revenuerecycling effect is estimated using the data on taxable income. I compare plants whose parent firm is in a loss position with plants whose parent firm is making a positive profit. If the latter plants experience a larger increase in productivity relative to the former plants, this productivity increase can be interpreted as the effect of revenue-recycling. This is because a reduction of the CIT rate is irrelevant for plants whose parent firm is in a loss position.

Using this strategy, the productivity effect is estimated by a propensity-score-weighted (PSW) difference-in-differences (DID) estimator, allowing for different treatment intensity across plants. This method augments the conventional DID estimator by allowing the treatment to be continuous and constructing estimates for the counterfactual from the ROC plants that resemble the BC 
plants. I first estimate the propensity scores using a rich set of observable pre-treatment plant characteristics, such as energy expenditures by various fuel types. I then use these propensity scores as weights to re-weight the distributions of the control plants in the estimation so that the plants from $\mathrm{BC}$ and $\mathrm{ROC}$ are similar in the pre-treatment period. Larger weights are given to plants that are more similar to plants in BC. In addition, I exploit the panel structure of the data by including various fixed effects to control for possible unobserved confounding factors, such as commodity price shocks, provincial geographic characteristics, and plant-specific managerial ability.

Using this approach, I find that BC's revenue-neutral carbon tax had a statistically significant negative carbon tax effect and positive revenue-recycling effect on manufacturing plants' productivity. On average, the carbon tax effect reduced productivity annually by $1.2 \%$ while the revenue-recycling effect increased productivity by $0.2 \%$, offsetting the negative carbon tax effect by approximately $20 \%$. The policy led to a net loss in productivity by $1 \%$. Yet, once I allow for heterogeneity, some plants experienced a net gain in productivity. These plants are the ones with a positive taxable income, but little carbon tax expenditure. For those plants, the productivity dividend hypothesis was supported. These findings provide evidence that recycling tax revenues through the reductions of the CIT rates can alleviate some negative productivity impacts from the carbon tax, and may lead to a net gain in productivity.

To put this in context, one can interpret these declines in productivity in terms of output (value-added). Assuming that inputs are held constant, on average, plant's output fell annually by $\$ 150,000$ in response to the policy. ${ }^{3}$ Without the CIT reduction, output would have declined by $\$ 160,000$, implying that recycling tax revenues through the reduction of CIT helped save output by $\$ 10,000$. By aggregating plant-level estimates, the finding suggests that BC's manufacturing output fell by $\$ 440$ million annually while the CIT reduction saved output by $\$ 25$ million.

This paper makes several contributions. Firstly, this paper develops a new hypothesis related to the double dividend hypothesis of environmental tax reforms. The traditional double dividend hypothesis suggests that the revenue-neutral substitution of the environmental tax for existing distortionary taxes leads to welfare or employment gains (Goulder, 1995). ${ }^{4}$ The PDH introduces a new possibility that revenue-recycling could also enhance productivity in addition to welfare and employment.

Furthermore, this paper estimates the revenue-recycling effect of an environmental tax, providing the first empirical test of the double dividend hypothesis in terms of productivity. No study in the literature has ever separately estimated both the carbon tax and revenue-recycling effects. The empirical approach used in this paper can be applied to estimate these two effects of environmental

\footnotetext{
${ }^{3}$ This is calculated as taking the average of plant-level output effects. The plant-level output effect is calculated as the difference between the counterfactual output $\left(=Y_{i} /\left(1-\% \Delta \mathrm{TFP}_{i}\right)\right.$, e.g., if the productivity effect is $-0.2 \%$ with $\$ 1$ million observed output, the counterfactual output is $\$ 1.002$ million.

${ }^{4}$ The effect could also be zero.
} 
taxes in general.

Secondly, this paper contributes to the broader literature on the productivity impacts of environmental policies. ${ }^{5}$ There are two types of environmental policies, command-and-control and market-based policies. Early studies have mostly focused on the former policy, e.g., the US Clean Air Act, and found that environmental regulations hamper productivity in narrowly defined subindustries within the manufacturing sector. ${ }^{6}$ More recently, Greenstone, List and Syverson (2012) have conducted a large-scale study of the 1970 US Clean Air Act Amendments using the plantlevel data covering the entire US manufacturing sector. They found that plants in regulated counties experienced a decline in TFP by $4.8 \%$.

While this literature is relatively extensive, there is little work examining the productivity effect of market-based policy, e.g., carbon pricing policies. Commins et al. (2011) and Lutz (2016) have both investigated the European Union Emission Trading System (EU-ETS) while Martin, de Preux and Wagner (2014) examined the UK energy tax. What is different about the market-based policy is that it provides incentives for polluters to respond to the policy in a flexible fashion. Commins et al. found that the first phase of the EU-ETS negatively affected European manufacturing firms' TFP. ${ }^{7}$ On the other hand, Lutz found the EU-ETS had a positive productivity effect during the first phase, but no effect during the second phase on German manufacturing firms. ${ }^{8}$ Martin, de Preux and Wagner also found no effect of the energy tax on UK manufacturing plants. Although the empirical evidence is limited, the productivity effects of the carbon pricing policies seem to be much less detrimental than those of command-and-control policies. This may be exactly due to the incentives provided by the policy for innovations and investments to improve input efficiency. This paper adds to this literature by showing that such incentives can be provided by recycling the tax revenues raised by the policy. Thus, this paper shows the importance of estimating both the carbon tax and revenue-recycling effects. Estimating both effects separately allows me to evaluate another important channel through which market-based policies may positively affect productivity.

Thirdly, this paper improves upon previous studies by constructing a measure of TFP more accurately. I do this by employing a semi-parametric estimation method proposed by Ackerberg, Caves and Frazer (2015) - henceforth ACF. I further revised the ACF method by following De

\footnotetext{
${ }^{5}$ See Koźluk and Zipperer (2015) and Dechezlepretre and Sato (2017) for the survey of this literature.

${ }^{6}$ One exception is Berman and Bui (2001). They examined a stricter air quality regulation imposed on the Los Angeles Air Basin and found a positive productivity effect in oil refineries. Although their empirical estimate was positive, it was statistically insignificant, and its confidence interval ranged from $19 \%$ to $-9 \%$. This result is consistent with the results found in Greenstone, List and Syverson (2012). Their estimate for the refinery sector was also statistically insignificant and its confidence interval ranged from $2 \%$ to $-3 \%$.

${ }^{7}$ The credibility of the findings of Commins et al. (2011) has been questioned by many papers as their treatment variable is defined at the sector-level. Their estimates may be severely biased due to the measurement errors and confounding sector shocks.

${ }^{8}$ The first phase of the EU-ETS was an experimental phase when the price of allowances was zero due to the excess supply. Thus, the second phase might be seen as the actual policy.
} 
Loecker (2007) and Lutz (2016). As a response to the policy involves investment, I must allow the policy to influence a plant's future productivity. To do so, I directly enter the policy into the productivity process. I also enter important plant heterogeneity that is related to behavioral responses to carbon tax, such as energy efficiency. In addition, this paper further improves the measure of TFP by using direct capital input data. This addresses an issue in estimating the production function when there is a measurement error in capital input (Collard-Wexler and De Loecker, 2016)

The remainder of the paper is structured as follows. Section 2 describes the design of the BC carbon tax. Section 3 defines the Productivity Dividend Hypothesis (PDH). I provide a simple model to explain the PDH. Section 4 presents the research design while section 5 explains the data. The empirical findings are presented in section 6. Section 7 discusses the counterfactual experiment where the tax revenue is recycled entirely through the CIT reduction. Finally, section 8 concludes. More general treatment of the model, detailed exploration of data, and additional robustness checks are in the Appendix.

\section{Background of the BC Carbon Tax}

The Ministry of Finance formally announced the implementation of carbon tax in their February 2008 budget plan. Only five months later, the tax was implemented on July 1st, 2008. The announcement surprised the public given the past political actions taken by the Liberal government (Harrison, 2013). The tax was originally criticized by northern and rural communities, arguing that tax burden might fall on them unfairly due to their colder climate. Even with some negative reactions, polls indicated that a majority of voters in BC supported the introduction of carbon tax. Thus far, despite the regime change from the Liberal Party to the New Democratic Party after the 2017 general election, the carbon tax has survived since the announcement and implementation.

The BC carbon tax is levied on the carbon content of all fossil fuels initially at $\$ 10 / \mathrm{tCO}_{2} \mathrm{e}$. The rate increased by $\$ 5 / \mathrm{t} \mathrm{CO}_{2} \mathrm{e}$ annually until it reached $\$ 30$ in 2012, making it the highest carbon tax in the world (Murray and Rivers, 2015). The rate was kept at $\$ 30$ until 2018 when it increased to $\$ 35$ on April 1. It will continue to annually increase by $\$ 5$ and reach $\$ 50$ in 2021 (Ministry of Finance, 2017). These increases are set to meet the carbon pricing requirements in the PanCanadian Framework on Clean Growth and Climate Change. This framework is a collective plan set out by the federal government to reduce emissions in Canada. British Columbia joined this framework in 2016. Under this framework, the carbon tax rate is required to be at $\$ 50$ by 2022. The BC carbon tax rate will reach this requirement in 2021 and will be kept at $\$ 50$ for 2022 .

As each fuel has a different carbon content, the rate is adjusted accordingly. For example, the carbon tax increased the price of gasoline by 2.34 cents per liter, rising gradually to 6.67 cents per liter in 2012 (Ministry of Finance, 2010). Increasing the tax rate gradually allows consumers to 
adjust their fuel usage slowly and minimize the financial burden from the tax.

In designing carbon pricing policy, certain exemptions are often made to avoid potential negative impacts to the economy. ${ }^{9}$ The exemptions are considered to address the concerns raised by the public and policymakers about losing competitiveness of regulated industries. At the same time, such compromises could be costly and lead to welfare losses due to the tax base erosion and increases of dead-weight loss (Böhringer and Rutherford, 1997). On the other hand, the BC carbon tax was designed initially with no exemptions, making the tax base broad. ${ }^{10}$

One of the unique aspects of the BC carbon tax is the revenue-neutrality. It is meant not only to minimize the potential adverse impact on the economy, but also to gain more support from the business community. Although business leaders expressed their support for the tax when they were approached by the Premier's office in late 2007, their support was contingent on the revenueneutrality. According to the Budget and Fiscal Plan (Ministry of Finance, 2015), the carbon tax raised about $\$ 1.2$ billion revenue annually since 2012 when the tax rate has stopped increasing at $\$ 30 / \mathrm{CO}_{2} \mathrm{e}$. These revenues are used to reduce the rate of personal and corporate income taxes and provide lump-sum transfers to low-income households. In detail, the personal income tax was reduced by 5 percent over the first two years for the two lowest income brackets (i.e., those earning less than $\$ 70,000$ per year) while the general and small corporate income taxes were reduced from 12 to 10 percent and 4.5 to 2.5 percent over the first three years, respectively (Ministry of Finance, 2008). ${ }^{11}$ In addition, a one-time Climate Action Dividend of $\$ 100$ per adult was provided in the initial year to help begin the transition to a lower-carbon lifestyle. To respond to the concerns raised by northern and rural communities, as of the 2011 tax year they are given a further benefit of $\$ 200$.

Although the government had designed this policy to be revenue-neutral, tax credits have been exceeding tax revenues since its implementation, an average excess of $\$ 128$ million over the first six years. The government has no intention of making the policy a part of the province's stimulus package. This discrepancy simply stems from failing to accurately estimate the expected revenue from the carbon tax. The estimated revenues have been lower than anticipated since the implementation due to the much higher decline in consumption of fossil fuels. Although the policy has

\footnotetext{
${ }^{9}$ For example, manufacturing and horticulture sectors are entirely exempted from the energy tax in Sweden while various transport sectors are exempt from the carbon tax in Norway (see Ekins and Speck (1999) for more examples of exemptions in Europe).

${ }^{10}$ In March 2012, a carbon tax relief was granted to commercial greenhouse growers to protect the competitiveness of agricultural industries against producers in the United States and Mexico (Murray and Rivers, 2015). Temporary relief of \$7.6 million was provided in 2012, and then the relief program was made into a permanent program in 2013. As of January 1, 2014, the purchase of colored gasoline and colored diesel fuel used for farm purposes are exempted. For further information, see http:www.gov.bc.ca/agri/.

${ }^{11}$ These made BC's corporate and personal income taxes the lowest in Canada. In fact, BC has tied with Alberta and New Brunswick for the lowest corporate tax rate, and has had the lowest personal income tax rate in Canada, but for only those earnings up to $\$ 119,000$ (Elgie and McClay, 2013).
} 
been revenue-negative, given that the excesses account only for less than 1 percent of BC's total tax revenue, I treat it as revenue-neutral in this analysis to be consistent with the intention of the BC government.

\section{The Productivity Dividend Hypothesis}

In this section, I briefly explain how a revenue-neutral carbon tax affects the productivity of manufacturing plants. ${ }^{12}$ A simple model motivates my empirical method discussed in Section 4.

Consider a partial equilibrium model with an iso-elastic demand for manufacturing goods:

$$
x=p^{-\sigma} B
$$

where $B$ is a constant representing aggregate quantity and price indexes, and $p$ is the price for the manufacturing goods.

Following Copeland and Taylor (1994), I assume there is a joint production technology for manufacturing plants: ${ }^{13}$

$$
\begin{aligned}
x & =A(1-\theta) F(K, L) \\
Z & =\varphi(\theta) F(K, L)
\end{aligned}
$$

where $x$ is manufacturing output and $Z$ is emission. ${ }^{14} \mathrm{I}$ assume that capital $(K)$ and labor $(L)$ are used to produce the potential output, $F(K, L)$. We can think of $x$ to be the net output because some are allocated to abatement. $\varphi(\theta)$ is an abatement function, satisfying $\varphi(0)=1, \varphi(1)=0$, and $d \varphi / d \theta<0 . \theta \in[0,1]$ is a fraction of inputs allocated to abatement. This means that the level of emission decreases with abatement, but at the cost of output.

Now following Forslid, Okubo and Ulltveit-Moe (2018), I express the abatement function of Copeland and Taylor (1994) as follows::

$$
\varphi(\theta)=\frac{(1-\theta)^{1 / \alpha}}{\Omega\left(I_{A}\right)}
$$

with $0<a<1$, and $\Omega\left(I_{A}\right)$ is the abatement augmenting technology, which is a function of abatement investment, $I_{A}$. It satisfies $d \Omega\left(I_{A}\right) / d I_{A}>0$ and is the reciprocal of the amount of emission

\footnotetext{
${ }^{12}$ I am grateful for my advisors, Kenneth J. McKenzie and M. Scott Taylor, for their valuable suggestions that have helped to improve this section.

${ }^{13}$ This is a joint production as producing one unit of output $(F)$ produces $x$ unit of emission, i.e., $x=A F(K, L)$ and $z=x$ if there is no abatement.

${ }^{14}$ Technically, the input augmenting technology, $A$, is applied to all inputs including emission. Thus, $A Z=$ $\varphi(\theta) A F(K, L)$.
} 
produced per output. ${ }^{15}$ This can be interpreted as a technological parameter for the abatement activity, i.e., an increase in $\Omega$ (.) is an improvement in the abatement technology. Eq.(3.4) reflects that plants can reduce their emissions by increasing $\theta$ or increasing the abatement investment. From Eq.(3.2), TFP can be expressed as $A(1-\theta)$. This implies that TFP increases with less resources allocated to the abatement activities.

By solving plant's problem, I show below how a revenue-neutral carbon tax affects the term, $(1-\theta)$. Using Eq.(3.2) and Eq.(3.3), output can be shown to be:

$$
x=A\left(\Omega\left(I_{A}\right) Z\right)^{a} F(K, L)^{1-a}
$$

With this formulation, one can think of $Z$ as an input and re-interpret it as energy. ${ }^{16}$ Further, let $e \equiv Z / x$ be energy intensity. Substituting $Z=e x$ into Eq.(3.5), and then solving for $x$ yields:

$$
x=A^{1 / 1-\alpha}\left(\Omega\left(I_{A}\right) e\right)^{\alpha /(1-\alpha)} F
$$

This shows that $A(1-\theta)=A^{1 / 1-\alpha}\left(\Omega\left(I_{A}\right) e\right)^{\alpha /(1-\alpha)}$. There are four decision processes that a plant goes through. First, the plant chooses how much to invest in abatement given the optimal pricing rule. Second, it sets its optimal pricing rule given abatement investments. Third, it chooses how much to abatement. Lastly, it chooses how much capital and labor to use to produce output. Thus, I solve backward to find an expression for plant's TFP, specifically $\Omega\left(I_{A}\right)$ and $e$, as a function of the carbon tax and corporate income tax (CIT).

\section{Cost minimization}

The minimum cost of producing a unit of $F$ can be found by solving the following problem:

$$
c^{F}(\tilde{r}, \tilde{w})=\min _{(k, l)}\{\tilde{w} l+\tilde{r} k: F(k, l)=1\}
$$

where $\tilde{r} \equiv\left(1-\lambda_{k} t^{c}\right) r$ and $\tilde{w} \equiv\left(1-t^{c}\right) w . r$ and $w$ are the prices of capital and labor, respectively. $t^{c}$ is the CIT rate. Following McKenzie and Ferede (2017), I assume that labor cost is fully deductible for tax purposes while only a portion $\lambda_{k} \geq 0$ of the capital cost is deductible.

\footnotetext{
${ }^{15}$ This parameter is 1 in Copeland and Taylor (1994) as they assume one unit of gross output produces one unit of emission.

${ }^{16}$ A concept of abatement in Copeland and Taylor (1994) is relevant here although regulation they consider is either emission tax or emission standard. Once I interpret $Z$ as energy and $\theta$ as a fraction of inputs allocated to energy-saving activities, such as R\&D expenditure allocated to energy-saving technology, the formulation of Copeland and Taylor (1994) is still valid. Tombe and Winter (2015) argue that "one might loosely interpret abatement as any costly activity that lowers the use of emissions-relevant energy, such as substitution between different fuel types." For this reason, investment in energy-saving technology, fuel switching, and factor substitution can all be interpreted as abatement in the definition of Copeland and Taylor (1994).
} 
$\lambda_{k}$ is a highly stylized representation of many CIT systems, intending to reflect the distortionary features of the CIT with regard to capital. The typical case would be $\lambda_{k}<1$ because the real cost of capital is not fully deductible. This is because only the nominal cost of debt finance is fully deductible. $\lambda_{k}>1$ is also possible when the tax system subsidizes capital. ${ }^{17}$ When $\lambda_{k}=1$, the full opportunity of cost of capital is deducted, and the CIT is a tax on economic profit (i.e., the CIT is not distortionary).

I assume that $F(k, l)=k^{\beta} l^{1-\beta}$. Then the cost function can be shown as:

$$
c^{F}(\tilde{r}, \tilde{w})=\kappa_{\beta} \tilde{r}^{\beta} \tilde{w}^{1-\beta}
$$

where $\kappa_{\beta} \equiv \beta^{-\beta}(1-\beta)^{\beta-1}$. Next, the plant determines how much to abate by solving the following cost minimization problem:

$$
c^{x}\left(\tilde{\tau}, c^{F}\right)=\min _{(z, F)}\left\{\tilde{\tau} z+c^{F}(\tilde{r}, \tilde{w}) F: A\left(\Omega\left(I_{A}\right) z\right)^{\alpha} F^{1-\alpha}=1\right\}
$$

where $\tilde{\tau} \equiv\left(1-t^{c}\right) \tau . \tau$ is the carbon tax inclusive energy price. ${ }^{18}$ I assume that energy cost is fully deductible for the tax purpose. Solving the cost minimization problem yields the conditional input function for energy and cost function:

$$
\begin{gathered}
z=\frac{1}{A \Omega\left(I_{A}\right)^{\alpha}}\left(\frac{\alpha}{1-\alpha} \frac{c^{F}}{\tilde{\tau}}\right)^{1-\alpha} \\
c^{x}\left(\tilde{\tau}, c^{F}\right)=\kappa_{a} A^{-1} \Omega\left(I_{A}\right)^{-\alpha} c^{F^{1-\alpha}} \tilde{\tau}^{\alpha}
\end{gathered}
$$

where $\kappa_{a} \equiv \alpha^{-\alpha}(1-\alpha)^{\alpha-1}$. Then, using the definition of energy intensity, Eq.(3.10) can be plugged into Eq.(3.6) as $Z / x=z=e$, and I can express TFP as a function of the abatement technology, carbon tax, and CIT:

$$
\mathrm{TFP}=A \underbrace{\left(\frac{\alpha}{1-\alpha}\right)^{\alpha}\left(\Omega\left(I_{A}\right) \frac{c^{F}}{\tilde{\tau}}\right)^{\alpha}}_{(1-\theta)}
$$

This shows that the abatement technology plays an important role in the productivity effect of the revenue-neutral carbon tax.

\footnotetext{
${ }^{17} \lambda_{k}>1$ is possible due to accelerated depreciation, investment allowances, investment tax credits, etc (McKenzie and Ferede, 2017).

${ }^{18}$ Here I am abstracting away from any changes in the tax-exclusive energy price. Thus, all the changes in the carbon tax inclusive energy price are due to the changes in the carbon tax rate. Henceforth, I call $\tau$ carbon tax.
} 


\section{Profit maximization}

Next, the plant sets the pricing rule given the abatement investment, and then chooses how much to invest in abatement given the pricing rule.

\section{Pricing rule}

Profit maximization by a monopolistic competitive manufacturing plant yields a pricing rule:

$$
p=\frac{\sigma}{\sigma-1} \frac{c^{x}}{1-t^{c}}
$$

Using Eq.(3.1) and Eq.(3.13), plant's profit can be expressed as:

$$
\pi=B(1-\sigma)^{\sigma-1} \sigma^{-\sigma}\left(1-t^{c}\right)^{-\sigma} c^{x^{1-\sigma}}-\left(1-t^{c}\right) I_{A}
$$

Here, similar to labor cost, I assume that the abatement investment cost is fully deductible. ${ }^{19}$

\section{Optimal abatement investment}

Finally, I derive an expression for $I_{A}$ as a function of $\tau$ and $t^{c}$. Following Forslid, Okubo and Ulltveit-Moe (2018), I assume that $\Omega\left(I_{A}\right)=I_{A}^{\rho}$ with $\rho>0$. Plugging Eq.(3.11) into Eq.(3.14), and then maximizing plant's profit with respect to abatement investment $I_{A}$ yield:

$$
I_{A}=A^{\frac{\sigma-1}{\gamma}} \Gamma^{\frac{1}{\gamma}} \tau^{-\frac{\alpha(\sigma-1)}{\gamma}}\left(\frac{1-\lambda_{k} t^{c}}{1-t^{c}}\right)^{-\frac{\beta(1-\alpha)(\sigma-1)}{\gamma}}
$$

where $\Gamma \equiv \alpha \rho B \sigma^{-\sigma}(\sigma-1)^{\sigma}\left(\kappa_{a} \kappa_{\beta}^{1-\alpha}\right)^{1-\sigma}\left(r^{\beta} w^{1-\beta}\right)^{(1-\alpha)(1-\sigma)}$ and $\gamma \equiv 1-\alpha \rho(\sigma-1)>0 .{ }^{20}$ Before plugging Eq.(3.15) back into Eq.(3.12) to discuss the productivity effect of the abatement investment, it is worth interpreting Eq.(3.15). Notice that when the costs of capital investments are fully deductible, i.e., $\lambda_{k}=1$, Eq.(3.15) becomes independent of the CIT. This is simply because when the CIT is levied on the pure profit, there is no distortion in the capital investment market.

Eq.(3.15) shows that the abatement investment is a decreasing function of carbon tax. However, Forslid, Okubo and Ulltveit-Moe (2018) point out that the effect of carbon tax on the abatement investment is ambiguous because carbon tax indirectly affects the abatement investment through the market competition, i.e., through $\Gamma$. If the plant's competitors pay more carbon tax, then it provides the plant an incentive to invest more in abatement.

On the other hand, the abatement investment is a decreasing function of the CIT. ${ }^{21}$ This implies $^{2}$

\footnotetext{
${ }^{19}$ Alternatively, I can also allow the abatement investment cost to be not fully deductible like capital cost. See Appendix A for more.

${ }^{20}$ In order to satisfy the second order condition of the profit maximization problem, $\gamma$ has to be positive. See Appendix A for the verification.

${ }^{21}$ See Appendix A for the verification.
} 
that the reduction of the CIT rate has a positive effect on abatement investment. ${ }^{22}$

Finally, plugging Eq.(3.15) into Eq.(3.12) yields:

$$
\mathrm{TFP}=A^{1 / \gamma} \underbrace{\tilde{\Gamma} \tau^{-\frac{\alpha}{\gamma}}}_{\text {Carbon tax }} \underbrace{\left(\frac{1-\lambda_{k} t^{c}}{1-t^{c}}\right)^{-\frac{\mu}{\gamma}}}_{\text {Revenue-recycling }}
$$

where $\tilde{\Gamma} \equiv\left(\frac{\alpha}{1-\alpha}\right)^{\alpha} \Gamma^{\frac{\alpha \rho}{\gamma}}\left(\kappa_{\beta} r^{\beta} w^{1-\beta}\right)^{\alpha}$ and $\mu \equiv \alpha \beta(\rho(\sigma-1)-1)$.

Besides the Hick-neutral technology parameter, $A$, Eq.(3.16) shows that there are two channels through which revenue-neutral carbon tax affects TFP. ${ }^{23}$ First, paying tax on energy purchased has a direct effect on TFP. I refer to it as the carbon tax effect. Eq.(3.16) shows that the carbon tax effect on productivity is ambiguous as carbon tax also affects abatement investment through the market competition, $\Gamma$, hence positively affecting TFP. ${ }^{24}$ There are two opposing channels within this carbon tax effect, a positive effect from the increases in abatement investment and a negative effect from the resource diversion.

Second, a decline in the CIT rate indirectly affects TFP. I refer to it as the revenue-recycling effect. Eq.(3.16) shows that the revenue-recycling effect increases TFP when $1 \leq \rho(\sigma-1)$. This means that the reduction of the CIT will likely to have a positive impact on TFP when the abatement technology improves faster with the abatement investment, and the goods are more substitutable. The revenue-recycling effect positively affects TFP by reducing the distortion in the capital market created by the CIT. Notice again that when the costs of capital are fully deductible, Eq.(3.16) becomes independent of the CIT. This suggests that the revenue-recycling effect of carbon tax on productivity comes entirely from the distortionary nature of the CIT.

With these two effects, it is clear that the productivity effect of the revenue-neutral carbon tax could go either direction. Yet, it could positively affect the plant's TFP. To summarize my model predictions, I develop a (empirically testable) hypothesis:

Hypothesis I: Recycling tax revenues by reducing corporate income tax rates increases productivityenhancing investments.

\footnotetext{
${ }^{22}$ In addition, lowering the CIT rate increases investments in general. Lowering the user costs of capital encourages plants to invest more. This may make plants more productivity through the increase in $A$.

${ }^{23}$ In addition, one could also imagine that plants might substitute away from fuels to non-fuel inputs in response to the carbon tax. This channel could be linked to the changes in $\alpha$. However, given that $\alpha$ is affecting Eq.(3.16) in much more complex fashion, I assume that $\alpha$ is constant in this paper. I also abstract away from the TFP effect through wage $(w)$ and rental rate $(r)$. As the incidence of the CIT may fall onto labor in terms of wages, the reduction of the CIT rate may also positively affect the plant's TFP through a higher wage. On the other hand, the rental rate is unlikely to respond to the policy because it is determined at the world market (e.g., small open economy assumption).

${ }^{24}$ This model prediction can also be related to the Porter hypothesis, i.e., carbon tax positively affects productivity through increases in investment.
} 
Hypothesis II: If the revenue-recycling increases productivity more than the carbon tax lowers productivity by diverting resources away from production, the policy achieves a net productivity gain.

I name this two-part hypothesis the "Productivity Dividend Hypothesis" (PDH). The first part of the PDH is only about the revenue-recycling effect. One may need to test whether the revenuerecycling through the CIT reduction increases investments, and thus productivity. In this paper, I evaluate whether the revenue-recycling has a positive productivity effect. Then when the positive revenue-recycling effect exceeds or completely offsets the negative carbon tax effect, the policy supports the PDH. ${ }^{25}$

Furthermore, as this has an obvious connection to the double dividend hypothesis of environmental tax reforms, when a policy achieves both emission reduction and productivity enhancement, such a policy offers a double dividend. I call this the "Productivity Double Dividend (PDD) Hypothesis." This hypothesis is similar to the employment double dividend hypothesis when the second dividend is employment gains. Although these are defined specifically with carbon taxes, this can be applied to any environmental taxes that recycle the tax revenues via the tax substitutions as well.

In the next section, I take Eq.(3.16) to data and estimate the productivity effect of the BC carbon tax to evaluate the PDH. A TFP equation can be approximated with a linear function as:

$$
\mathrm{TFP}_{i t}=\beta_{1} \tau_{i t}+\beta_{2}\left(1-t_{i t}^{c}\right)+\epsilon_{i t}
$$

where $\tau_{i t}$ is the carbon tax rate and $\left(1-t_{i t}^{c}\right)$ is the net-of-the CIT rate for plant $i$ at time $t . \beta_{1}$ captures the carbon tax effect and $\beta_{2}$ captures the revenue-recycling effect through the reduction of the CIT rate. However, I do not observe plant-level carbon tax rate or CIT rate because these taxes are only levied at provincial-level. Thus, I take advantage of rich data and interact these provincial tax rates with plant-level characteristics to approximate $\tau_{i t}$ and $\left(1-t_{i t}^{c}\right)$. I discuss the detail in the next section.

\footnotetext{
${ }^{25}$ There is one another case when a policy can achieve a net productivity gain. That is when both carbon tax and revenue-recycling effects are positive. When the carbon tax effect is positive, that provides support for the Porter hypothesis. The combination of the Porter hypothesis and the positive revenue-recycling effect can also support the PDH.
} 


\section{Research Design}

\subsection{Empirical Framework}

This section discusses the econometric design to estimate the effect of the $\mathrm{BC}$ carbon tax on manufacturing plants' productivity. I employ a difference-in-differences (DID) estimator, i.e., comparing the plants in BC with plants in the rest of Canada (ROC). The simple model illustrated that the productivity effect depends on the carbon tax and CIT rates, affecting the decisions on resource allocations including abatement investment. With available data, I augment the DID estimation with the information from the model, using plant-level heterogeneity to proxy plant-level policy exposures. ${ }^{26}$ I estimate the following equation:

$$
\ln \operatorname{TFP}_{i j p t}=\beta_{1} \operatorname{CTax}_{i p t}+\beta_{2} \operatorname{Recycling}_{i p t}+X_{p t}+\phi_{i}+\lambda_{j t}+\epsilon_{i j p t}
$$

where $\ln \mathrm{TFP}_{i j p t}$ is the $\log$ of TFP for plant $i$ in industry $j$ in province $p$ at time $t$, which is estimated using the semiparametric estimation method proposed by Ackerberg, Caves and Frazer (2015). ${ }^{27}$ This method addresses the problem of endogeneity in the input decisions and is argued to be the most robust among other estimation methods (Van Biesebroeck, 2007). I define CTax ipt $\equiv$ $\left(\sum_{f}\right.$ Fuel $\left._{i}^{f} \times \operatorname{CTax}_{p t}^{f}\right) / \mathrm{VA}_{i}$ and Recycling $i p t \equiv \mathbb{1}\left(\mathrm{TI}_{i}>0\right) \times\left(1-\mathrm{CIT}_{p t}\right)$. Let Fuel ${ }_{i}$ be an average consumption of fuel $f$ for plant $i$ from the pre-policy period (2004-2007), CTax $f_{p t}^{f}$ be a fuel-specific carbon tax variable (e.g., for gasoline, 0 if $t=$ pre-carbon tax period for BC plants, 2.34 cents/liter if $t=2008,3.51$ if $t=2009,4.45$ in $t=2010,5.56$ if $t=2011$, and 6.67 if $t=2012$ for $\mathrm{BC}$ plants. 0 for ROC plants for all $t$ ), and $\mathrm{VA}_{i}$ be a pre-policy average value-added for plant $i$. $\mathrm{TI}_{i}$ is a pre-policy average taxable corporate income for plant $i{ }^{28} \mathrm{CIT}_{p t}$ is $\mathrm{BC}^{\text {'s corporate }}$ income tax rate. $\mathbb{1}\left(\mathrm{TI}_{i}>0\right)$ is an indicator function that takes one when average taxable income during the pre-policy period is strictly positive. ${ }^{29} X_{p t}$ is a control variable at province-level, such as provincial GDP. $\phi_{i}$ are plant fixed effects that capture time-invariant plant heterogeneity while $\lambda_{j t}$ are industry-specific time fixed effects that controls for industry specific shocks at given year. Finally, $\epsilon_{i j p t}$ is an error term that captures idiosyncratic changes in productivity.

The Recycling ipt term allows me to evaluate the first part of the PDH while the first two terms

\footnotetext{
${ }^{26}$ This augmentation is inspired by Yamazaki (2017).

${ }^{27}$ See Online Appendix D.D.1 for further details on the construction of TFP measure. De Loecker (2007) and Lutz (2016) further extend the OP/LP/ACF method by allowing determinants of production to enter the productivity process. Such determinants include the export status (De Loecker, 2007), R\&D status (Doraszelski and Jaumandreu, 2013), and the EU-ETS (Lutz, 2016).

${ }^{28}$ If a plant is owned by a multi-plant firm, $\mathrm{TI}_{i} \equiv s_{i} \times \mathrm{TI}_{e}$ with $\sum_{i \in e} s_{i}=1$ where $s_{i}$ is the output share of plant $i$ within firm $e$ and $\mathrm{TI}_{e}$ is the taxable income for firm $e$.

${ }^{29}$ I also test the robustness of the estimates using different thresholds and find similar results, presented in Table C.2 in Appendix C.
} 
together evaluate the second part of the PDH of the BC carbon tax. The first term measures the carbon tax effect $\left(\beta_{1}\right)$ while the second term measures the revenue-recycling effect $\left(\beta_{2}\right)$. The carbon tax effect is the productivity effect coming directly from taxing the energy purchased. Calculating the fuel-specific carbon tax expenditure allows me to exploit the plant-level variation in the financial tax burden. I hypothesize that the higher $\mathrm{CTax}_{i p t}$ is, the larger the tax burden is for this plant. $\beta_{1}$ can also measure the productivity effect of the carbon tax without the reduction of the corporate income tax. The revenue-recycling effect is the productivity effect coming from the reduction of the CIT rate. Interacting the positive taxable corporate income indicator with the net-of-the CIT rate allows me to observe how much of the financial benefits a (tax-paying) plant receives from the revenue-recycling of this carbon tax. This is based on a logic that plants with non-positive taxable income (i.e., in-loss plants) would not receive any benefits from the revenue-recycling. This allows me to exploit the plant-level variation in the financial benefit of the policy.

The coefficients of interest are $\beta_{1}$ and $\beta_{2}$. In particular, the approximate percentage change in productivity for plant $i$ at time $t$ in response to the carbon tax is calculated by $\alpha_{i t} \equiv 100 \times$ $\left(\hat{\beta}_{1} \Delta \operatorname{CTax}_{i p t}+\hat{\beta}_{2} \Delta\right.$ Recycling $\left._{i p t}\right) .{ }^{30}$ The estimated coefficient $\hat{\beta}_{1}$ and $\hat{\beta}_{2}$ are estimated from across plant $\times$ province comparisons over time.

To properly estimate the productivity effect, the underlying identification assumption requires that there be no factors other than the carbon tax creating differences in changes in productivity between plants in BC and plants in other provinces. ${ }^{31}$ This assumption will be violated if the government of BC concurrently implements other policy induced by the carbon tax that affects all plants in BC differently while no other provinces implement a similar policy. Another important identification assumption is common trends. This assumption requires that the changes in productivity for plants in BC (treatment group) and other provinces (control group) would follow the same time trend in the absence of the carbon tax. This implies that the plants in BC and ROC are similar and thus would experience the same level of productivity effect if they are all subject to the carbon tax. Although including the fixed effects and time-varying control variables can control for various confounding factors, the estimates will be biased if treated and control plants are inherently different, especially in the pre-treatment period. ${ }^{32}$

To ensure the similarity between treated plants (BC) and control plants (ROC), I take advantage of the rich data and estimate Eq.(4.1) with weights based on propensity scores - PSW-DID esti-

\footnotetext{
${ }^{30}$ As the estimation equation is in the semi-elasticity (log-linear) form, the exact percentage change in productivity is calculated by $100 \times\left(e^{\hat{\beta}_{1} \Delta \mathrm{CTax}_{i p t}+\hat{\beta}_{2} \Delta \operatorname{Recycling}_{i p t}}-1\right)$.

${ }^{31}$ Additionally, the identification requires that treated and control plants are similar in their plant characteristics so that they would respond to the policy in a similar fashion. This assumption may, especially, be called into question for identifying the revenue-recycling effect because one may argue that tax-paying and in-loss plants operate differently. In Appendix B.B.2, I explore this concern and show that these plants are comparable.

${ }^{32}$ To ensure that the results are not biased by the pre-treatment trends (effects), I show that the treatment variables in Eq.(4.1) are not statistically significant in the pre-treatment period, presented in Table C.1 in Appendix C.
} 
mator. More weights are given to control plants that resemble treated plants. The weight of one is given to the treated plans while the weights, $\frac{p_{i}(X)}{1-p_{i}(X)}$, are given to the control plants. ${ }^{33}$ The propensity scores are estimated using a probit model. The observable pre-treatment plant characteristics that are related to the carbon tax are used as predictors of the treatment assignment. ${ }^{34} \mathrm{~A}$ full list of covariates used for estimating the propensity scores is presented in Table B.2 in Appendix C. ${ }^{35}$ Re-weighting plants based on this rich set of observable pre-treatment characteristics allows me to compare similar treated and control plants in many dimensions and credibly isolate the effect of the policy on manufacturing productivity. ${ }^{36}$

\section{Data Sources}

To evaluate the productivity dividend hypothesis, two of Statistics Canada's confidential dataset are linked, the Annual Survey of Manufactures (ASM) and General Index of Financial Information (GIFI). ${ }^{37}$ The ASM is an annual survey that contains information on manufacturing activities for all manufacturing locations in Canada. ${ }^{38}$ I obtain information on output, employment, and intermediates (raw materials and energy consumptions) from the ASM. What is missing from the ASM is information on capital, which I obtain from the GIFI. ${ }^{39}$ The GIFI is an extensive list of financial statement items, which businesses use to file their T2 corporate income tax return. One advantage of the GIFI is that unlike other studies that must rely on the perpetual inventory method or a proxy to construct a capital stock variable, it provides a direct measure of capital input. This helps to address an issue in estimating the production function when there is a measurement error in input variables.

From the ASM-GIFI linked data, I take advantage of the rich data and obtain necessary variables to employ the PSW-DID method in estimating Eq.(4.1), such as energy expenditure by fuel types (e.g., electricity, gasoline, natural gas, etc), taxable corporate income, plant age, export, and etc.

\footnotetext{
${ }^{33} p_{i}(X)$ is the estimated probability for plant $i$ being treated conditioning on the covariates, $X$. The weights are normalized such that their average is equal to one among control plants.

${ }^{34}$ Only the period of 2004-2006 is used to estimate the propensity score. This is because by using all pre-treatment years, the common trend assumption will hold by construction, which is not meaningful. I leave out 2007 to see if the common trend assumption will still hold despite matching only on the 2004-2006 period.

${ }^{35}$ I also included a square term of the covariates to improve the balancing (Caliendo and Kopeinig, 2008; Dehejia and Wahba, 2002).

${ }^{36}$ I demonstrate the effectiveness of the propensity score re-weighting in Appendix B.B.3.

${ }^{37}$ I explain the detail of the linkage of these two data in Appendix B.B.1.

${ }^{38}$ Although the ASM is a survey data, over the sample period it is essentially a census with data on smaller firms being filled with administrative records. The further details of the ASM are provided in http://www23.statcan.gc.ca/ $\mathrm{imdb} / \mathrm{p} 2 \mathrm{SV}$.pl?Function=getSurvey \&Id=504733.

${ }^{39}$ The further details of the GIFI are provided in https://www.canada.ca/en/revenue-agency/services/ forms-publications/publications/rc4088/general-index-financial-information-gifi.html.
} 


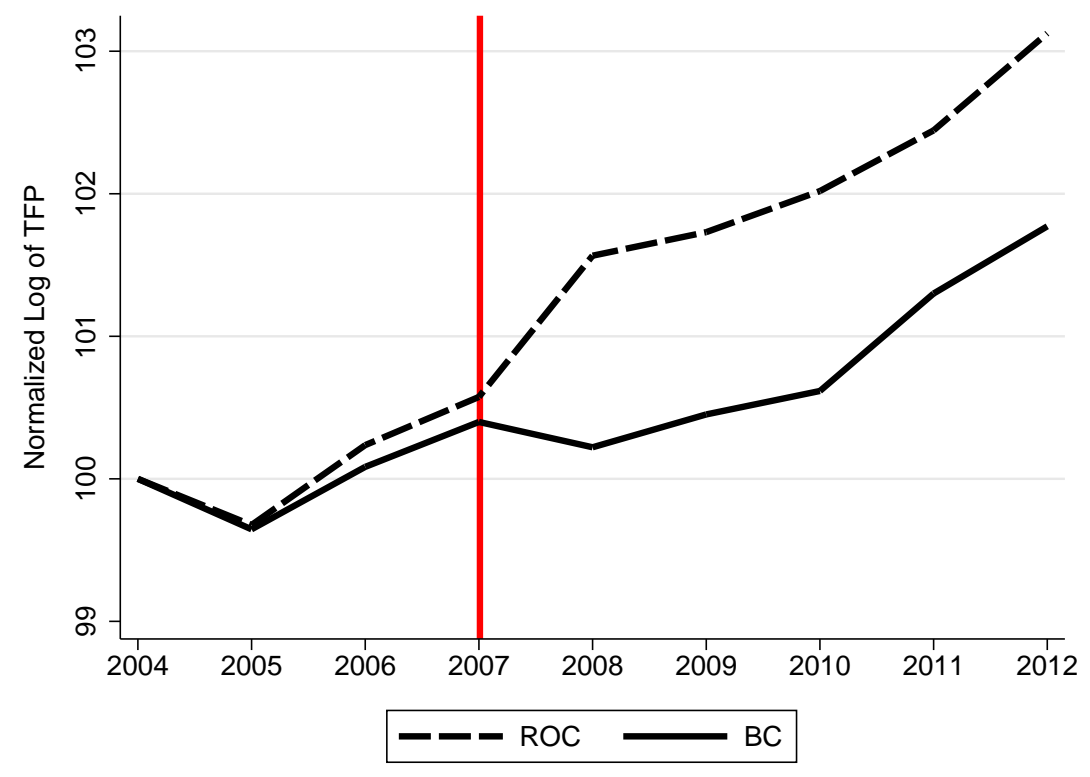

Figure 1: Trends of TFP

Note: This figure plots the trends of TFP for BC and ROC. ROC (Adjusted) is the same as ROC, but added the prepolicy average gap of TFP between BC and ROC.

Source: Author's calculation.

There are about 77,000 plants (10,000 plants in BC and 65,000 plants in ROC), 86 subindustries (4 digit NAICS level), 13 regions (10 provinces and 3 territories), and 9 years (20042012) in the data. ${ }^{40}$

\section{Estimated TFP}

Before I present the main results, I provide summary statistics of the estimated TFP, presented in Figure 1 and Table 1. Figure 1 plots the trend of TFP for BC and ROC. Overall trends are increasing for both $\mathrm{BC}$ and $\mathrm{ROC}$ over the sample period, except there is a noticeable decline for $\mathrm{BC}$ in 2008. Many might argue that this could be due to the global financial crisis that took place at the same time as the implementation of the BC carbon tax. If so, we should expect to see a similar decline for ROC as well. However, we actually observe the opposite, i.e., TFP increased in 2008 for ROC. This is one suggestive evidence that the BC carbon tax might have contributed to this difference in TFP between BC and ROC.

In addition, to credibly identify the productivity effect of the policy, the pre-policy TFP trend between plants in BC and plants in ROC must be parallel. It is clear from Figure 1 that they are.

\footnotetext{
${ }^{40}$ Although the survey has been conducted annually since 1917 , there was a major change to its survey design in 2004. To preserve the consistency in the data, I decided to only use the 2004-2012 period. For further information about the changes in the survey, see http://www23.statcan.gc.ca/imdb/p2SV.pl?Function=getMainChange\&Id=3060.
} 
Table 1: Summary Statistics for the estimated productivity (lnTFP)

\begin{tabular}{|c|c|c|c|c|c|c|c|}
\hline & \multicolumn{3}{|c|}{ Level } & \multicolumn{4}{|c|}{ Growth } \\
\hline & $\mathrm{BC}$ & ROC & Difference & $\mathrm{BC}$ & ROC & Difference & $\begin{array}{c}\text { Standardized } \\
\text { Difference } \\
\end{array}$ \\
\hline Pre & $\begin{array}{c}9.86 \\
(0.78)\end{array}$ & $\begin{array}{c}9.85 \\
(0.83)\end{array}$ & $\begin{array}{l}0.010 \\
(0.01)\end{array}$ & $\begin{array}{l}0.192 \\
(6.01)\end{array}$ & $\begin{array}{l}0.343 \\
(6.69)\end{array}$ & $\begin{array}{c}-0.151 * * \\
(0.06)\end{array}$ & -0.024 \\
\hline 2004 & $\begin{array}{c}9.85 \\
(0.82)\end{array}$ & $\begin{array}{c}9.83 \\
(0.87)\end{array}$ & $\begin{array}{l}0.023 \\
(0.01)\end{array}$ & & & & \\
\hline 2005 & $\begin{array}{c}9.83 \\
(0.78)\end{array}$ & $\begin{array}{c}9.82 \\
(0.81)\end{array}$ & $\begin{array}{l}0.009 \\
(0.01)\end{array}$ & $\begin{array}{l}0.041 \\
(6.79)\end{array}$ & $\begin{array}{l}0.076 \\
(6.73)\end{array}$ & $\begin{array}{l}-0.035 \\
(0.13)\end{array}$ & -0.005 \\
\hline 2006 & $\begin{array}{c}9.87 \\
(0.76)\end{array}$ & $\begin{array}{c}9.86 \\
(0.79)\end{array}$ & $\begin{array}{l}0.008 \\
(0.01)\end{array}$ & $\begin{array}{l}0.452 \\
(5.87)\end{array}$ & $\begin{array}{l}0.532 \\
(6.06)\end{array}$ & $\begin{array}{c}-0.080 \\
(0.11)\end{array}$ & -0.013 \\
\hline 2007 & $\begin{array}{c}9.89 \\
(0.75)\end{array}$ & $\begin{array}{c}9.89 \\
(0.83)\end{array}$ & $\begin{array}{c}-0.002 \\
(0.01)\end{array}$ & $\begin{array}{l}0.084 \\
(5.31)\end{array}$ & $\begin{array}{l}0.419 \\
(7.22)\end{array}$ & $\begin{array}{c}-0.334 * * * \\
(0.10)\end{array}$ & -0.053 \\
\hline Post & $\begin{array}{c}9.91 \\
(0.79)\end{array}$ & $\begin{array}{l}10.00 \\
(0.79)\end{array}$ & $\begin{array}{c}-0.088 * * * \\
(0.01)\end{array}$ & & & & \\
\hline DID & & & $\begin{array}{c}-0.098 * * * \\
(0.01)\end{array}$ & & & & \\
\hline
\end{tabular}

Note: Standard deviations are in the parenthesis except values in the parenthesis for the column for Difference are standard errors. $T$-tests on the mean differences between $\mathrm{BC}$ and ROC are performed. A null hypothesis is that the difference in group means is zero. Standardized differences are calculated as $\frac{\bar{Y}_{\text {treated }}-\bar{Y}_{\text {control }}}{\sqrt{\left(s_{\text {treated }}^{2}+s_{\text {control }}^{2}\right) / 2}}$, and correct the $t$-statistics of the $T$-test for the sample size. The value for DID, reported in the last row, is calculated by taking the difference of time-differences (difference between pre- and post-policy) for BC and ROC.

After normalizing the trends, the trends start to deviate from each other in the same year as the implementation of the policy. I further performed $t$-tests on the difference in means during the precarbon tax years between BC and ROC, presented in Table 1. Differences in means of the level of productivity are not statistically different from zero. While the difference in means of the growth of productivity is statistically different from zero over the entire pre-policy period and 2007. While these results from the $t$-tests may raise a concern that the pre-policy TFP trend may not be parallel, many practitioners of the DID method claim that the $t$-test on the mean differences is misleading especially when the sample size is large (e.g., Imbens (2015)). As the $t$-statistics takes into account such a large sample size, a small difference in means between two groups can be statistically significant even if it is substantively small. To mitigate this issue, I also calculated the standardized differences for the growth of productivity to test the parallel trends, reported in the last column of Table 1. Unlike the $t$-statistics, the standardized differences are independent of the sample size. The standardized differences are substantially smaller. As the standardized differences being 
greater than 0.25 indicates that the mean differences are statistically different from zero (Stuart and Rubin, 2008), Table 1 illustrates that the pre-policy productivity trends between BC and ROC plants are parallel.

As a start, I calculated differences in TFP between BC and ROC before and after the policy, presented in the last row of Table 1. This simple calculation shows that manufacturing productivity declined by $10 \%$ in response to the carbon tax in BC. Now with this suggestive finding, I present the main results using the more rigorous econometric technique to identify the productivity effect of this policy.

\section{Results}

The results are presented in the following subsections. Section 6.6.1 presents estimates of Eq.(4.1) to evaluate the PDH while the rest of the subsections presents the results from robustness checks, heterogeneous effects, and dynamic effects. All analyses employ the propensity-scoreweighted DID estimator.

\subsection{Carbon Tax and Revenue-recycling Effects}

The results of three specifications based on Eq.(4.1) are reported in column 4 through 6 of Table 2. Each column reports coefficients estimated using a different level of the industry by year fixed effects, 2-digit NAICS by year, 3-digit NAICS by year, and 4-digit NAICS by year, respectively. These estimates are identified with clustered standard errors. ${ }^{41}$ In the last row, I present the $F$ statistics from the joint test for the significance of $\beta_{1}$ and $\beta_{2}$ together, i.e., $\mathrm{H}_{0}: \beta_{1}=\beta_{2}=0$.

Before I discuss the results from estimating Eq.(4.1), I briefly explain the importance of Eq.(4.1). An alternative to Eq.(4.1), one can employ a simpler version of Eq.(4.1), which has a similar taste to a conventional DID estimator:

$$
\ln \operatorname{TFP}_{i j p t}=\beta \operatorname{CTax}_{p t}+X_{p t}+\phi_{i}+\lambda_{j t}+\epsilon_{i j p t}
$$

where $\operatorname{CTax}_{p t}$ is a carbon tax variable (i.e., for BC plants 0 if $t=$ pre-carbon tax period, 10 if $t=$ 2008, 15 if $t=2009, \ldots, 30$ if $t=2012$ and 0 for ROC plants) and the rest is defined as in Eq.(4.1). While this approach is intuitive and straightforward, it is difficult to isolate the productivity effect

\footnotetext{
${ }^{41}$ Cameron and Miller (2015) suggest clustering at the broadest feasible level, which in this case the province-level. One may worry about too few cluster groups as there are only 10 provinces (including BC) in Canada. Alternatively, I could cluster at the industry by province-level to increase the number of cluster groups, which would ignore the within-province correlation. However, Mackinnon and Webb (2019) show that under-clustering (i.e., clustering at the industry by province) suffers from a severe over-rejection, implying that ignoring the within-province correlation is worse than having too few cluster groups.
} 
Table 2: Impact of the Carbon Tax on Plant Productivity

\begin{tabular}{|c|c|c|c|c|c|c|}
\hline & (1) & (2) & (3) & (4) & (5) & (6) \\
\hline $\operatorname{CTax}_{p t}$ & $\begin{array}{c}-0.0038^{* * * *} \\
(0.0004)\end{array}$ & $\begin{array}{c}-0.0034 * * * * \\
(0.0003)\end{array}$ & $\begin{array}{c}-0.0031 * * * * \\
(0.0003)\end{array}$ & & & \\
\hline $\operatorname{CTax}_{i p t}\left(\beta_{1}\right)$ & & & & $\begin{array}{c}-5.13 * * \\
(1.76)\end{array}$ & $\begin{array}{c}-8.21 * * * \\
(1.83)\end{array}$ & $\begin{array}{c}-7.35^{* * * *} \\
(1.30)\end{array}$ \\
\hline $\operatorname{Recycling}_{i p t}\left(\beta_{2}\right)$ & & & & $\begin{array}{c}0.155^{* * *} \\
(0.07)\end{array}$ & $\begin{array}{c}0.135^{*} \\
(0.07)\end{array}$ & $\begin{array}{l}0.13^{*} \\
(0.06)\end{array}$ \\
\hline \multicolumn{7}{|l|}{ Industry $\times$ time } \\
\hline 2-digit & $\mathrm{Y}$ & & & $\mathrm{Y}$ & & \\
\hline 3-digit & & $\mathrm{Y}$ & & & $\mathrm{Y}$ & \\
\hline 4-digit & & & $\mathrm{Y}$ & & & $\mathrm{Y}$ \\
\hline$N$ & 237,478 & 237,478 & 237,478 & 237,333 & 237,333 & 237,333 \\
\hline$R^{2}$ & 0.65 & 0.67 & 0.67 & 0.65 & 0.67 & 0.67 \\
\hline$F$-statistics & & & & 5.3 & 23.3 & 62.5 \\
\hline
\end{tabular}

Notes: Dependent variable is $\log$ of TFP. CTax ${ }_{p t}$ is a carbon tax variable (i.e., for BC plants 0 if $t=$ pre-carbon tax period, 10 if $t=2008,15$ if $t=2009, \ldots, 30$ if $t=2012$ and 0 for ROC plants.); $\mathrm{CTax}_{i p t} \equiv\left(\sum_{f}\right.$ Fuel $\left._{i}^{f} \times \mathrm{CTax}_{p t}^{f}\right) / \mathrm{VA}_{i} ;$ Fuel $_{i}$ is an average consumption of fuel $f$ for plant $i$ from the pre-policy period (2004-2007); CTax $f_{p t}^{f}$ is a fuel-specific carbon tax variable (e.g., for gasoline, 0 if $t=$ pre-carbon tax period for BC plants, 2.34 cents/liter if $t=2008,3.51$ if $t=2009,4.45$ in $t=2010,5.56$ if $t=2011$, and 6.67 if $t=2012$ for BC plants. 0 for ROC plants at all $t) ; \mathrm{VA}_{i p}$ is a pre-policy average value-added for plant $i$; Recycling $i p t \equiv \mathbb{1}\left(\mathrm{TI}_{i}>0\right) \times\left(1-\mathrm{CIT}_{p t}\right)$; $\mathrm{TI}_{i}$ is a pre-policy average taxable corporate income for plant $i$; CIT $_{p t}$ be BC's corporate income tax rate; $\mathbb{1}\left(\mathrm{TI}_{i}>0\right)$ is an indicator function that takes one when average taxable income during the pre-policy period is strictly positive. All specifications includes plant FE and provincial GDP as a control. Industry by time fixed effects is included in each specification at the different aggregationlevel, 2-digit NAICS by time, 3-digit NAICS by time, and 4-digit NAICS by time, respectively. To account for serial correlations and within sub-industry correlations, standard errors are clustered by province, reported in parentheses. The last row presents the $F$-statistics from the joint test for the significance of $\beta_{1}$ and $\beta_{2}$ together, i.e., $\mathrm{H}_{0}: \beta_{1}=\beta_{2}=0$.

*** Significant at the 1 percent level, ${ }^{* *}$ Significant at the 5 percent level, ${ }^{*}$ Significant at the 10 percent level.

for a casual interpretation, especially when many other macroeconomic events happened around the same time as the implementation of the $\mathrm{BC}$ carbon tax. Although some confounding factors can be captured by the fixed effects, any factors that are different across provinces and over time would bias the estimation. To mitigate this issue, I directly exploit plant-level variations in the policy exposures in Eq.(4.1). This also provides me more variations to clearly identify the effects.

The results based on Eq.(6.1) are reported in the first three columns of Table 2. These robust point estimates suggest that, on average (at $\$ 20$ carbon tax), the carbon tax decreases productivity annually by $6 \%$ during the sample period. Although the direction of the productivity effect is consistent with the results from estimating Eq.(4.1), the magnitude is much larger when plant 


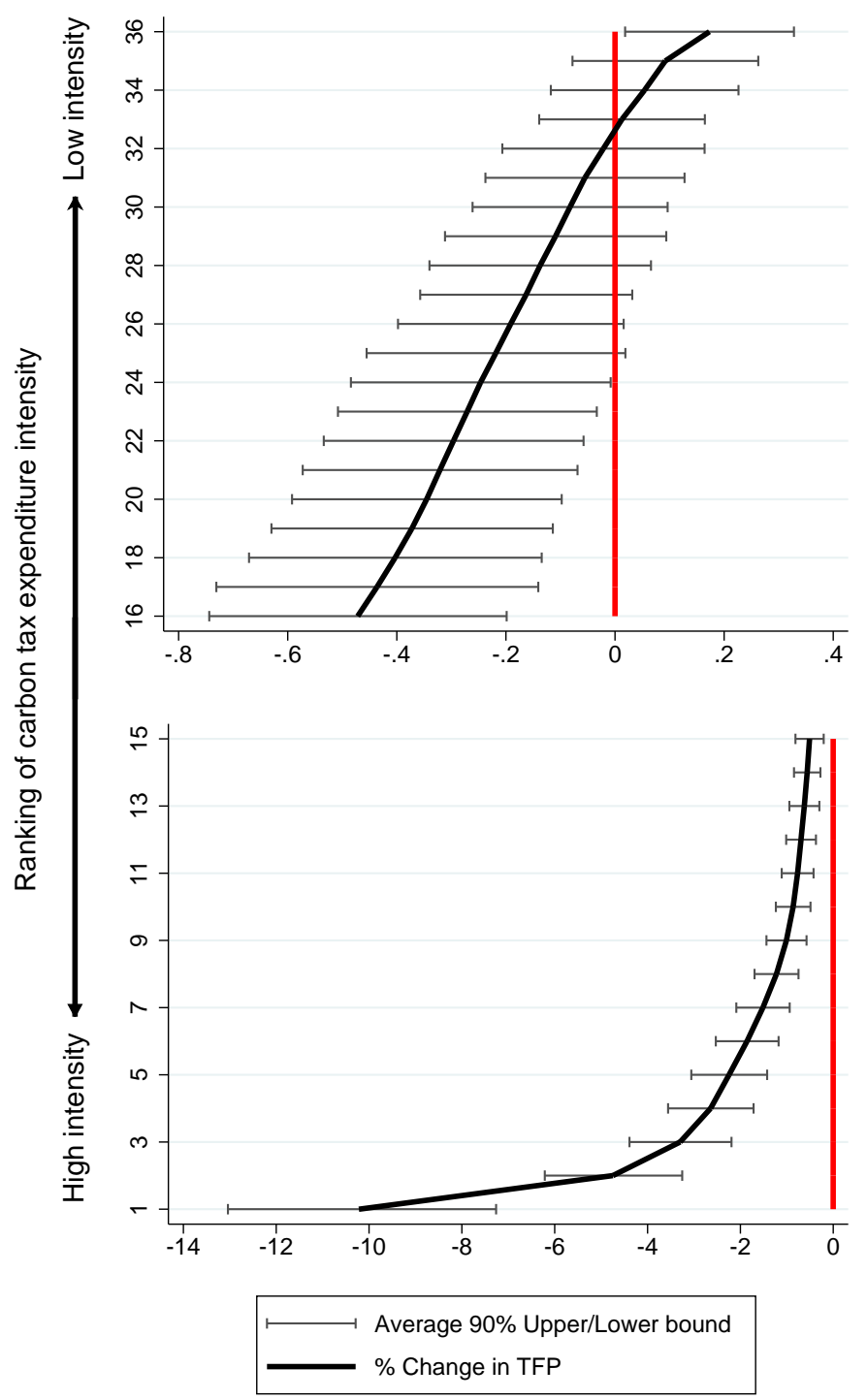

Figure 2: Distribution of Estimated Productivity Effects

Note: This figure plots the plant-level estimated TFP effects. To maintain confidentiality in conformity with Statistics Canada's Statistics Acts, the plant-level TFP effects and its corresponding upper and lower bounds are ranked and then averaged over 100 plants in the order.

Source: Author's calculation.

heterogeneity in policy exposures is ignored. This illustrates the importance of plant heterogeneity in estimating the productivity effect using Eq.(4.1).

Now I discuss the main results. A clear pattern emerged from these results, presented in the last three columns of Table 2. The results provide support for the first part of the PDH - the revenue-recycling effect positively affects productivity. Based on the coefficients from column 6 of Table 2, on average, the carbon tax effect reduced productivity annually by $1.2 \%$ while the 
revenue-recycling effect increased productivity by $0.2 \%$, leading to a net loss in productivity by $1 \%{ }^{42}$ This finding suggests that, on average, the revenue-recycling effect alleviated the negative effect from the carbon tax by approximately $20 \%$. This implies that recycling the tax revenues from the carbon tax to lower the CIT rates can improve the distortion in the capital market, positively affecting productivity.

As the positive revenue-recycling effect was not large enough, on average, to offset the negative carbon tax effect, the second part of the PDH was not supported. However, depending on the size of the carbon tax expenditure intensity, some plants experienced a net gain in their productivity. Figure 2 shows the distribution of the productivity effect. At the top of the figure, there are approximately 400 plants whose positive revenue-recycling effect was larger than its negative carbon tax effect. These plants are the ones with a relatively low carbon tax expenditure intensity. For these plants, the second part of the PDH was supported. To sum, recycling the tax revenues can alleviate some of the adverse effects of this policy on plants' productivity, and may even lead to a net productivity gain.

Another way to interpret the results is to translate these percentage changes in productivity to the changes in output (value-added). With the plant-level estimated productivity effect, on average, the output is reduced annually by $\$ 150,000$ in response to the policy. ${ }^{43}$ Although the reduction of the CIT rates helped plants save the output, on average, by $\$ 10,000$, the carbon tax reduced output by $\$ 160,000{ }^{44}$

To discuss the aggregate effect, I aggregated the plant-specific output effects. The finding suggests that BC's manufacturing output declined by $\$ 440$ million while it would have declined by $\$ 465$ million without the CIT reduction. Thus, the CIT reduction has saved output by \$25 million.

\subsection{Robustness Checks}

In this subsection, I probe the robustness of the estimates. Overall, I found little evidence that undermines the results reported in Section 6.6.1. ${ }^{45}$

\footnotetext{
${ }^{42}$ As the distribution of the estimated productivity effect is left-skewed, the mean and median productivity effects differ. In terms of median, the carbon tax effect reduced productivity by $0.6 \%$ while the revenue-recycling effect increased productivity by $0.2 \%$, leading to a net loss in productivity by $0.4 \%$. To maintain the confidentiality in conformity with Statistics Canada's Statistics Acts, I define median as a range between the $49^{\text {th }}$ and $51^{\text {st }}$ percentile.

${ }^{43}$ This is calculated as taking the average of plant-level output effects. The plant-level output effect is calculated as the difference between the counterfactual output $\left(=Y_{i} /\left(1-\left(\alpha_{i} / 100\right)\right)\right.$, e.g., if the productivity effect is $-0.2 \%$ with $\$ 1$ million observed output, the counterfactual output is $\$ 1.002$ million.) and the observed output. As the distribution of plant-level output is heavily right-skewed, the median might be more informative. In terms of median, the output is reduced by $\$ 4,300$.

${ }^{44}$ In terms of median, the carbon tax effect reduced output by $\$ 5,800$ while the revenue-recycling effect increased output by $\$ 1,500$. In the net, output declined by $\$ 4,300$.

${ }^{45} \mathrm{~A}$ series of additional robustness checks are presented in Appendix C and Online Appendix D.D.3
} 
Table 3: Testing the Robustness of the Estimates

\begin{tabular}{|c|c|c|c|c|}
\hline & \multirow{2}{*}{$\begin{array}{c}\text { Base } \\
(1)\end{array}$} & \multicolumn{3}{|c|}{ No Multi-plant Firms } \\
\hline & & (2) & (3) & (4) \\
\hline $\operatorname{CTax}_{i p t} \quad\left(\beta_{1}\right)$ & $\begin{array}{c}-7.35 * * * \\
(1.30)\end{array}$ & $\begin{array}{c}-17.26^{* * *} \\
(1.17)\end{array}$ & $\begin{array}{c}-18.48^{* * *} \\
(2.08)\end{array}$ & $\begin{array}{c}-12.57^{* * *} \\
(2.02)\end{array}$ \\
\hline $\operatorname{Recycling}_{i p t}\left(\beta_{2}\right)$ & $\begin{array}{l}0.13^{*} \\
(0.06)\end{array}$ & $\begin{array}{l}0.22 * * \\
(0.088)\end{array}$ & $\begin{array}{l}0.23 * * \\
(0.101)\end{array}$ & $\begin{array}{c}0.17 * \\
(0.099)\end{array}$ \\
\hline $\begin{aligned} \text { Industry } \times & \text { time } \\
& \text { 2-digit } \\
& \text { 3-digit } \\
& \text { 4-digit }\end{aligned}$ & Y & Y & $\mathrm{Y}$ & $\mathrm{Y}$ \\
\hline $\begin{array}{l}N \\
R^{2} \\
F \text {-statistics }\end{array}$ & $\begin{array}{c}237,333 \\
0.67 \\
62.5\end{array}$ & $\begin{array}{c}224,792 \\
0.68 \\
109\end{array}$ & $\begin{array}{c}224,792 \\
0.68 \\
43.3\end{array}$ & $\begin{array}{c}224,792 \\
0.66 \\
20.5\end{array}$ \\
\hline \multicolumn{5}{|c|}{$\begin{array}{l}\text { Notes: Treatment variables, CTax }{ }_{i p t} \text { and Recycling }{ }_{i p t} \text { are all defined as in Eq.(4.1). All } \\
\text { specifications includes plant FE, and provincial GDP as a control. To account for serial } \\
\text { correlations and within sub-industry correlations, standard errors are clustered by province, } \\
\text { reported in parentheses. No Multi-plant Firms means that I exclude plants that are owned by } \\
\text { a firm who owns multiple plants both in BC and ROC. From column } 2 \text { to } 4 \text { includes industry } \\
\text { by time FEs at the different level. } F \text {-statistics are for the joint test for the significance of } \beta_{1} \\
\text { and } \beta_{2} \text { together, i.e., } \mathrm{H}_{0}: \beta_{1}=\beta_{2}=0 \text {. } \\
10 \text { percent level. }\end{array}$} \\
\hline
\end{tabular}

\section{Excluding Contaminated Control Plants}

Identifying the productivity effects relies heavily on an assumption that the control plants are not affected by the treatment (i.e., stable unit treatment value assumption - SUTVA). ${ }^{46}$ Violating the SUTVA would bias my estimates. Such contaminations may happen if a firm owns multiple plants across provinces because the firm can minimize the tax burden by shifting production away from plants located in BC to plants located in the rest of Canada. Operational adjustments within a firm with plants across BC and ROC are easier and would be more likely to occur than across plants that do not share a common owner. To eliminate such adjustments in the estimation, I excluded plants that are owned by a multi-plant firm with plants both in BC and ROC. ${ }^{47}$

\footnotetext{
${ }^{46}$ Alternative way to test the validity of the SUTVA is to perform a placebo test, treating one of the non-BC provinces as a pseudo treatment group. I present the results in Table D. 1 in Online Appendix D.D.3. Of fourteen coefficients (two coefficients for seven provinces), the carbon tax effect for $\mathrm{AB}$ was statistically significant at 1 percent and negative while the carbon tax effect for ON and NS were significant at 5 percent and 10 percent, respectively, but positive. None of the coefficients for the revenue-recycling effect were statistically significant. However, in contrast to BC, no province had a pattern of sign and significance in line with the model.

${ }^{47}$ This does not exclude plants who are owned by a multi-plant firm with plants only in BC or ROC.
} 
Table 4: Productivity Effects using TFPQ

\begin{tabular}{|c|c|c|c|c|}
\hline & $\begin{array}{c}(1) \\
\text { TFPR }\end{array}$ & $\begin{array}{c}(2) \\
\text { TFPQ }\end{array}$ & $\begin{array}{c}(3) \\
\text { TFPQ }\end{array}$ & $\begin{array}{c}(4) \\
\text { TFPQ }\end{array}$ \\
\hline $\mathrm{CTax}_{i p t}$ & $\begin{array}{c}-7.35 * * * \\
(1.3)\end{array}$ & $\begin{array}{c}-7.15 * * \\
(2.59)\end{array}$ & $\begin{array}{c}-11.77^{* * *} \\
(2.71)\end{array}$ & $\begin{array}{c}-10.49^{* * *} \\
(1.90)\end{array}$ \\
\hline Recycling $_{i p t}$ & $\begin{array}{l}0.13 * \\
(0.06)\end{array}$ & $\begin{array}{c}0.24 * * \\
(0.10)\end{array}$ & $\begin{array}{l}0.21 * \\
(0.11)\end{array}$ & $\begin{array}{c}0.20 * * \\
(0.09)\end{array}$ \\
\hline $\begin{aligned} \text { Industry } \times & \text { time } \\
& \text { 2-digit } \\
& \text { 3-digit } \\
& \text { 4-digit }\end{aligned}$ & $\mathrm{Y}$ & Y & Y & $\mathrm{Y}$ \\
\hline $\begin{array}{l}N \\
R^{2} \\
F \text {-statistics }\end{array}$ & $\begin{array}{c}237,333 \\
0.67 \\
62.5\end{array}$ & $\begin{array}{c}237,333 \\
0.66 \\
4.26\end{array}$ & $\begin{array}{c}237,333 \\
0.67 \\
19.89\end{array}$ & $\begin{array}{c}237,333 \\
0.68 \\
59.37\end{array}$ \\
\hline
\end{tabular}

Notes: TFPR is log of revenue-based TFP while TFPQ is log of quantity-based TFP.

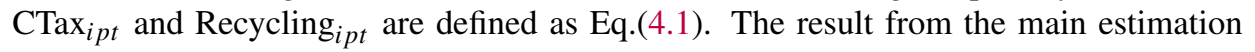
reported in column 6 of Table 2 is reported in column 1 as TFPR. All specifications includes plant FE and provincial GDP as a control. Industry by time fixed effects is included in each specification at the different aggregation-level, 2-digit NAICS by time, 3-digit NAICS by time, and 4-digit NAICS by time, respectively. To account for serial correlations and within sub-industry correlations, standard errors are clustered by province, reported in parentheses. The last row presents the $F$-statistics from the joint test for the significance of $\beta_{1}$ and $\beta_{2}$ together, i.e., $\mathrm{H}_{0}: \beta_{1}=\beta_{2}=0$.

*** Significant at the 1 percent level, ${ }^{* *}$ Significant at the 5 percent level, ${ }^{*}$ Significant at the 10 percent level.

The estimation results are reported in Table 3, which should be compared to the results of base specifications (column 6 of Table 2) presented in column 1 of Table 3. Despite the difference in the sample, the estimates are robust across specifications, and the signs of the coefficient on both carbon tax and revenue-recycling effects are preserved. I further explore this in Section 6.6.3 to see whether there is a heterogeneous effect between single-plant firms (plants) and multi-plant firms.

\section{Price Effects}

One of the difficulties in conducting a productivity analysis is that output is measured in revenue, not quantity. The exact problem with this is that plants may increase their price in response to the policy. I argue that this price effect may not be a major issue in this paper because a majority of plants in the sample are heavily traded internationally. This implies that their output prices are determined at the world market, not set by individual plants. This is especially true for Canadian manufacturing plants as Canada is considered as a small open economy. Nonetheless, I test this price effect by constructing the quantity-based TFP (TFPQ) and compare that with my revenue- 
based TFP (TFPR). I explain in detail how I construct TFPQ in Online Appendix D.D.2.

The results, presented in Table 4, suggest that the productivity effect of this policy is reasonably similar regardless of the choice of TFP measures. The signs and sizes of both carbon tax and revenue-recycling effects using TFPQ are similar to those of my base estimation with TFPR. Unlike other studies that also compared the productivity effects between TFPR and TFPQ (e.g., Greenstone, List and Syverson (2012); Tanaka, Yin and Jefferson (2014)), the difference in the productivity effect between TFPR and TFPQ identified in this paper is substantially small. This confirms my prior expectation that the price effect is not a major concern in this context.

\subsection{Heterogeneous Effects}

The analyses to this point have focused on the average effects of the revenue-neutral carbon tax on plant productivity. It is more realistic that the size of the productivity effects varies across different plants. Some plants are likely to be more affected by this policy than others. These differences might be attributed to the differences in plants' characteristics. To investigate such heterogeneous responses, I group plants into three dimensions. First, I allow the productivity effect to differ across large, medium, and small plants based on the size of their output. This is particularly important as the public worries that small plants might be disproportionately affected by the policy due to their inability to adjust. Second, following up on the robustness check section, I explore whether the productivity effect differs between the single-plant firms and multi-plant firms. Third, I separately estimate the productivity effect for young and old plants. This is based on a hypothesis that young plants are relatively more efficient and productive than old plants, allowing them to adjust to the policy more efficiently. The results from these heterogeneous effect analyses are reported in Table 5.

There are several interesting results worth discussing. First, the coefficient on the carbon tax effect for small plants is statistically insignificant, but positive while that on the revenue-recycling effect is statistically significant and positive. This suggests that small plants may be benefiting from the revenue-recycling of this policy without incurring substantial costs from the policy. This may increase the chance to support the PDH for these small plants. This finding could also imply that the public concern about these small businesses may be unwarranted. On the other hand, large plants are experiencing the statistically significant negative impact from the carbon tax effect and positive impact from the revenue-recycling effect, resulting in the net decline in their TFP. Despite a few of statistically insignificant coefficients, these results suggest that, on average (among each group), large and medium plants experienced a net loss in their productivity by 0.5 percent and 3.5 percent, respectively, while small plants experienced a net gain in their productivity by 0.7 
Table 5: Effects of the BC Carbon Tax by Different Plant Characteristics

\begin{tabular}{|c|c|c|c|c|c|c|c|}
\hline & \multicolumn{3}{|c|}{ Plant size } & \multirow{2}{*}{\multicolumn{2}{|c|}{$\frac{\text { Firm structure }}{\text { Single-plant Multi-plant }}$}} & \multicolumn{2}{|c|}{ Plant age } \\
\hline & Large & Medium & Small & & & Old & Young \\
\hline \multirow[t]{2}{*}{$\mathrm{CTax}_{i p t}$} & $-2.35 * *$ & $-24.99 * * *$ & 3.02 & $-15.57 * * *$ & -0.36 & $-8.02 * * *$ & $-3.36^{* *}$ \\
\hline & $(0.92)$ & $(2.52)$ & $(2.08)$ & (1.18) & $(1.18)$ & (1.37) & $(1.59)$ \\
\hline \multirow{2}{*}{ Recycling $_{i p t}$} & 0.02 & $0.33^{* *}$ & $0.23 *$ & $0.14 * *$ & $0.13 *$ & $0.16^{* *}$ & -0.005 \\
\hline & $(0.05)$ & $(0.12)$ & $(0.12)$ & $(0.06)$ & $(0.08)$ & $(0.08)$ & $(0.03)$ \\
\hline$N$ & 77305 & 79445 & 54793 & 188755 & 48578 & 184027 & 53306 \\
\hline \# of Firms & 11131 & 11131 & 11131 & 29552 & 8131 & 29892 & 7209 \\
\hline$R^{2}$ & \multicolumn{3}{|c|}{0.67} & \multicolumn{2}{|c|}{0.67} & \multicolumn{2}{|c|}{0.68} \\
\hline$F$-statistics & 10.76 & 61.5 & 1.92 & 284 & 6.4 & 72 & 3.17 \\
\hline
\end{tabular}

Notes: Plant size is determined by output. A plant is large if its output is above the 70th percentile, medium if its output is between the 35th and 65th percentiles, and small if its output is below the 25th percentile. Under Firm structure, I compare plants that are singly owned with plants whose parental firm owns multiple-plants. For Plant age, I compare plants that are less than 9 year old at 2008 with plants that are older than 9 year old. The former plants are defined as young plants while the latter plants are defined as old plants. All specifications includes plant FE, industry (4-digit NAICS) by time FE, and provincial GDP as a control. To account for serial correlations and within sub-industry correlations, standard errors are clustered by province, reported in parentheses. The last rows present the $F$-statistics from the joint test for the significance of $\beta$ s together, e.g., $\mathrm{H}_{0}: \beta_{1}^{j}=\beta_{2}^{j}=0$ where $j$ is the group category, e.g., large plants.

*** Significant at the 1 percent level, ** Significant at the 5 percent level, * Significant at the 10 percent level. 
percent. $^{48}$

The remaining results are consistent with my prior expectations. As shown in the robustness checks, single-plant firms are more negatively affected by the carbon tax effect than multi-plant firms. On average, single-plant firms experienced a net loss in their productivity by 2 percent. ${ }^{49}$ What is interesting here is that multi-plant firms are not affected by the policy. These findings suggest that it is not the small plants that are affected more negatively, but rather single-plant firms. Given that a majority of small plants are often singly-owned, the negative productivity effect on the single-plant firms is expected to be driven by the medium single-plant firms.

Similarly as expected, old-plants are more (negatively) affected by the policy than young plants. On average, old plants experienced a net loss in their productivity by 1.2 percent while young plants experienced a net loss by 0.5 percent. ${ }^{50}$ This finding may imply that there are more rooms for productivity improvements of old plants if the policy is designed to encourage them to invest and modernize their production technology. A surprising finding here is that young plants are not responding (i.e., almost zero effect) to the revenue-recycling. This could imply that young plants are likely to be at the optimal (efficient) point in their investment decision, allowing them not to respond to the reduction of the CIT rates.

\subsection{Dynamic Effects}

All the specifications above assume that plants respond to the policy contemporaneously. While this may be true, it is also likely that some adjustments, such as investments, may take some time and their impact on productivity may be pronounced later. This may be, especially, true for the market-based policy, such as a carbon tax, because it provides incentives for plants to respond. It may take some time for plants to best respond to such incentives, hence affecting productivity with lags. I explore the possibility of such long-term responses by adding one and two years of the lagged carbon tax and revenue-recycling effects in Eq.(4.1). One cautionary note here is that I would argue that what I discuss here is suggestive for the long-term responses because the time span used in this paper is too short to be considered long-run.

The results are presented in Table 6. Column 1 is taken from column 6 of Table 2, which should be used as a baseline for comparisons. One of the most interesting findings here is that there is a positive lag carbon tax effect. When the one-year lag of carbon tax effect and that of revenue-recycling effect are included, the contemporaneous carbon tax effect became more nega-

\footnotetext{
${ }^{48}$ In terms of median, large and medium plants experienced a net loss in their productivity by 0.15 percent and 1.5 percent, respectively, while small plants experienced a net gain in their productivity by 0.5 percent.

${ }^{49}$ In terms of median, the net loss is 0.9 percent. The results suggest that the carbon tax effect and revenue-recycling effect canceled each other out, resulting in almost zero effect on their productivity.

${ }^{50}$ In terms of median, old plants experienced the net loss by 0.4 percent while young plants experienced the net loss by 0.2 percent.
} 
Table 6: Dynamic Effects - Allowing for Lags

\begin{tabular}{lccc}
\hline \hline & $(1)$ & $(2)$ & $(3)$ \\
\hline CTax $_{i p t}$ & $-7.4^{* * *}$ & $-12.9^{* * *}$ & $-7.2^{* *}$ \\
& $(1.3)$ & $(2.5)$ & $(2.4)$ \\
CTax & & $9.1^{* * *} t-1$ & 2.4 \\
& & $(1.96)$ & $(1.94)$ \\
CTax $_{i p t-2}$ & & & $3.13^{*}$ \\
& & & $(1.7)$ \\
Recycling $_{i p t}$ & & & \\
& $0.13^{*}$ & $0.12^{*}$ & $0.14^{* * *}$ \\
Recycling $_{i p t-1}$ & $(0.06)$ & $(0.06)$ & $(0.03)$ \\
& & 0.02 & 0.06 \\
Recycling $_{i p t-2}$ & & $(0.07)$ & $(0.14)$ \\
& & & $-0.12^{*}$ \\
$N$ & & & $(0.06)$ \\
$R^{2}$ & & & \\
$F$-statistics (All) & & & \\
\hline \hline
\end{tabular}

Notes: Treatment variables, CTax ${ }_{i p t}$, and Recycling ${ }_{i p t}$ are defined as Eq.(4.1). All specifications includes plant FE, industry (4-digit NAICS) by time FE, and provincial GDP as a control. To account for serial correlations and within sub-industry correlations, standard errors are clustered by province, reported in parentheses. The last row presents the $F$-statistics from the joint test for the significance of $\beta_{1}$ and $\beta_{2}$ together, i.e., $\mathrm{H}_{0}: \beta_{1}=\beta_{2}=0$.

*** Significant at the 1 percent level, ${ }^{* *}$ Significant at the 5 percent level, ${ }^{*}$ Significant at the 10 percent level.

tive than the estimate without the lag. The one-year lag carbon tax effect is statistically significant and positive. The contemporaneous and one-year lag revenue-recycling effects are both positive; however, only the contemporaneous effect is statistically significant. Including both one and two years of lag generates similar results as the one-year lag estimates except now two-year lag effects are statistically significant. These findings suggest that this may be evidence for both the PDH and Porter hypothesis in the long-run. ${ }^{51}$ 


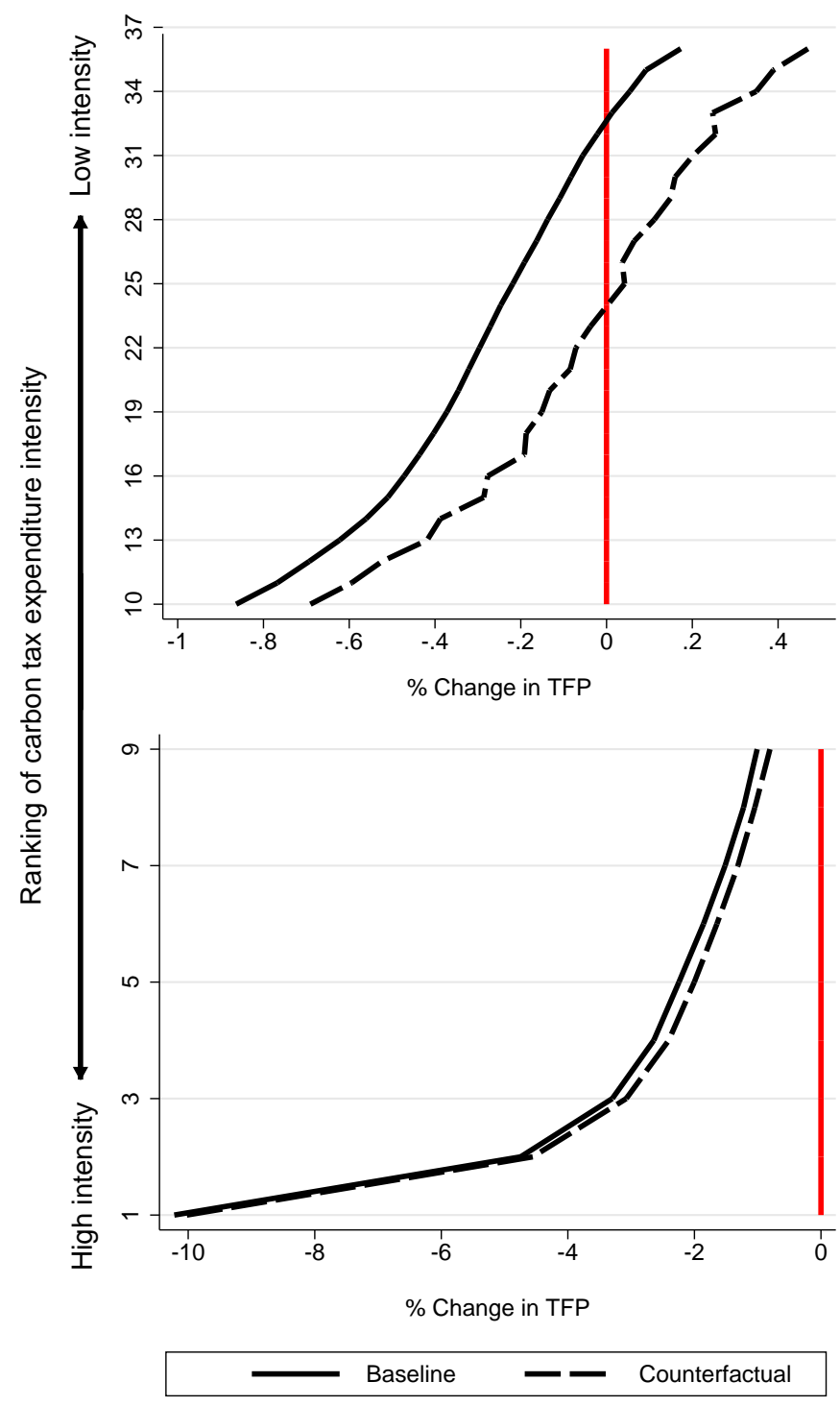

Figure 3: Comparison of the Distributions of Productivity Effects

Note: This figure plots the plant-level estimated TFP effects (baseline) and counterfactual TFP effects. To maintain confidentiality in conformity with Statistics Canada's Statistics Acts, the plant-level TFP effects and its counterfactuals are ranked and then averaged over 100 plants in the order.

Source: Author's calculation.

\section{Discussion}

All the analyses above have shown that recycling the carbon tax revenue by reducing the rates of corporate income tax positively affects productivity. However, at the current rates, the average

\footnotetext{
${ }^{51}$ The Porter hypothesis is about strict environmental regulations encouraging investment and innovation, thus positively affecting productivity. This paper suggests that the Porter hypothesis may be more realistic for the long-run as only the lagged carbon tax effects are positive, not the contemporaneous effect.
} 
net productivity effect was negative. During the $2008-2012$ period, on average $50 \%$ of the tax revenue was recycled back to the economy through the reduction of the CIT. The other half was recycled through the reduction of the personal income tax and the lump-sum transfer to low-income households. Instead of recycling the tax revenues this way, one can recycle the revenues entirely through the reduction of the CIT. This may increase the size of the positive revenue-recycling effect, increasing the chance of supporting the PDH. To explore this possibility, I take the estimates from column 6 of Table 2 and then increase the reduction rates of the CIT. ${ }^{52}$ The results are presented in Figure 3.

As expected, the distribution of productivity effects slightly shifts to the right, expanding the positive region. The number of plants who experienced the net gain in their productivity is approximately tripled from the baseline. Yet, the average net productivity effect is negative $(-0.8 \%)$. One interesting finding from this counterfactual experiment is that when the carbon tax rate is at $\$ 10 / \mathrm{CO}_{2} \mathrm{e}$, the median net productivity effect is positive (on the order of $0.06 \%$ ). These findings emphasize that the economic impacts of a policy depend heavily on how the revenues are returned to the economy because it is possible to design a policy that supports the productivity dividend hypothesis.

\section{Conclusion}

Theoretical research hypothesizes that environmental taxes can achieve both emission reductions and welfare (employment) gains. The non-environmental benefits of such policies come from recycling tax revenues to reduce rates of distortionary taxes. This paper developed a new hypothesis - the "Productivity Dividend Hypothesis" - and empirically showed that recycling revenues has a potential to improve productivity.

The model I present in this paper suggests that taxing energy purchases diverts productive resources away from production, reducing productivity. On the other hand, reducing corporate income tax rates encourages productivity-enhancing investments. If the latter is larger than the former, the carbon tax can generate a net gain in productivity.

Using a unique micro-level data on manufacturing activities and corporate income tax, I find that the BC carbon tax had a negative carbon tax effect and positive revenue-recycling effect on

\footnotetext{
${ }^{52}$ To do this, I made a few assumptions. First, I assume that the total carbon tax revenue raised does not change between the actual reduction rates and the counterfactual reduction rates of the CIT. Second, the amount of corporate taxable income does not change between the actual and counterfactual. With these two assumptions, I calculated the counterfactual reduction rates of the CIT. I do this by taking the ratio between the level of the total carbon tax revenue recycled and the level of the revenue recycled via the reduction of the CIT rates. Then I multiply the ratio to the actual reduction rates of the CIT to obtain the counterfactual reduction rates. I set the counterfactual reduction rates to be as follows: 3.3 percentage point reduction in $2008,3.5$ percentage point reduction in 2010 , and 4.4 percentage point reduction in 2011.
} 
plants' productivity. However, the net effect of this policy was negative. On average, the carbon tax effect reduced productivity annually by $1.2 \%$ while the revenue-recycling effect increased productivity by $0.2 \%$, leading to a net loss in productivity by $1 \%$. In the aggregate, the declines in productivity by the carbon tax correspond to output reductions by $\$ 465$ million while the CIT reduction saves output by $\$ 25$ million, resulting in a net loss by $\$ 440$ million. These findings suggest that recycling tax revenues alleviates some of the adverse effects of the policy on plants' productivity, but not all. Given that the complete offset is not the exact intention of the revenue-recycling, it is expected to see some plants' productivity falling while others experience productivity enhancement.

How are these negative productivity effects compared to the benefits of the policy? Aggregate emission from the manufacturing sector in $\mathrm{BC}$ has declined by $4 \%$ relative to the manufacturing sector in the rest of Canada after the implementation of the policy. ${ }^{53}$ The reduction of productivity by $1 \%$ seems reasonably small. ${ }^{54}$ Thus, the public concern regarding emission reductions being achieved at the cost of economic growth may be unwarranted.

One caveat of this paper is that the negative productivity effect I identified in this paper is mainly a short-term response. As I pointed out in my simple model, investing in abatement (energy-saving activities) plays an important role in generating a positive effect on productivity. However, the potential efficiency improvements from this investment may not be immediately reflected in one's productivity. It is possible that plants suffer from carbon tax in the short-run while managing to become more efficient and productive than before the implementation of the policy in the long-run. The results presented in Section 6.6.4 supports this claim although more data is required to fully analyze the long-term effect.

Finally, I conclude this paper by emphasizing the importance of the revenue-neutrality of carbon tax policy. This paper, for the first time, provided evidence that recycling revenues through the reduction of corporate income taxes can alleviate the adverse effects of the policy, possibly leading to productivity enhancement. The empirical exercise conducted in this paper to evaluate the "Productivity Dividend Hypothesis" can be tested more broadly for any environmental taxes that attempt to keep the policy revenue-neutral by the tax substitutions. Furthermore, an empirical investigation of the "Productivity Double Dividend Hypothesis" of environmental taxes would also bring fruitful contributions to both the literature and public policy.

\footnotetext{
${ }^{53}$ This is calculated by using the facility-level emission data from Environment and Climate Change Canada. https://www.canada.ca/en/environment-climate-change/services/climate-change/greenhouse-gas-emissions/ facility-reporting/data.html

${ }^{54}$ This is not to say that this reduction of emission is solely due to the policy.
} 


\section{References}

Ackerberg, Daniel A., Kevin Caves, and Garth Frazer. 2015. "Identification Properties of Recent Production Function Estimators.” Econometrica, 83(6): 2411-2451.

Berman, Eli, and Linda T M Bui. 2001. "Environmental Regulation and Productivity : Evidence From Oil Refineries.” Review of Economics and Statistics, 83(3): 498-510.

Böhringer, Christoph, and Thomas F Rutherford. 1997. "Carbon Tax with Exemptions in an Open Economy: A General Equilibrium Analysis of the German Tax Initiative." Journal of Environmental Economics and Management, 32: 189-203.

Bosquet, Benoit. 2000. "Environmental tax reform: does it work? A survey of the empirical evidence." Ecological economics, 34: 19-32.

Caliendo, Marco, and Sabine Kopeinig. 2008. "Some Practical Guidance for the Implementation of Propensity Score Matching." Journal of Economic Surveys, 22(1): 31-72.

Cameron, A. Colin, and Douglas L. Miller. 2015. "A practitioner's guide to cluster-robust inference.” Journal of Human Resources, 50(2): 317-372.

Collard-Wexler, Allan, and Jan De Loecker. 2016. "Production Function Estimation with Measurement Error in Inputs.” NBER Working Paper.

Commins, Nicola, Sean Lyons, Marc Schiffbauer, and Richard S.J. Tol. 2011. "Climate policy \& Corporate Behavior." The Energy Journal, 32(4): 51-68.

Copeland, Brian R., and M. Scott Taylor. 1994. "North-South Trade and the Environment." Quarterly Journal of Economics, 109(3): 755-787.

Dechezlepretre, Antoine, and Misato Sato. 2017. "The impacts of environmental regulations on competitiveness." Review of Environmental Economics and Policy, 11(2): 183-206.

Dehejia, Rajeev H, and Sadek Wahba. 2002. "Propensity Score-Matching Methods for Nonexperimental Causal Studies." The Review of Economics and Statistics, 84(February): 151-161.

De Loecker, Jan. 2007. "Do exports generate higher productivity? Evidence from Slovenia." Journal of International Economics, 73(1): 69-98.

De Loecker, Jan. 2013. "Detecting learning by exporting." American Economic Journal: Microeconomics, 5(3): 1-21.

Doraszelski, Ulrich, and Jordi Jaumandreu. 2013. "R\&D and productivity: Estimating endogenous productivity." Review of Economic Studies, 80(4): 1338-1383.

Ekins, Paul, and Stefan Speck. 1999. "Competitiveness and Exemptions From Environmental Taxes in Europe." Environmental and Resource Economics, 13(4): 369-396. 
Elgie, Stewart, and Jessica McClay. 2013. "BC's Carbon Tax Shift Is Working Well after Four Years (Attention Ottawa).” Canadian Public Policy, 39(s2): S1—-S10.

Forslid, Rikard, Toshihiro Okubo, and Karen Helene Ulltveit-Moe. 2018. "Why are firms that export cleaner? International trade, abatement and environmental emissions." Journal of Environmental Economics and Management, 91: 166-183.

Foster, Lucia, John Haltiwanger, and Chad Syverson. 2008. "Reallocation, Firm Turnover, and Efficiency: Selection on Productivity or Profitability?" The American Economic Review, 98(1): 394-425.

Goulder, Lawrence H. 1995. "Environmental Taxation and the Double Dividend: A Reader's Guide." International Tax and Public Finance, 2: 157-183.

Greenstone, Michael, John A List, and Chad Syverson. 2012. "The Effects of Environmental Regulation on the Competitiveness of U.S. Manufacturing." NBER Working Paper.

Harrison, Kathryn. 2013. "The Political Economy of British Columbia's Carbon Tax." OECD Environment Working Papers, 63.

Heartwell, Colin. 2012. "Manufacturing BC - Outlook 2020." Public affairs Committee of Canadian Manufacturers \& Exporters, CME2012.

Hsieh, Chang-Tai, and Peter J. Klenow. 2009. "Misallocation and Manufacturing TFP in China and India." The Quarterly Journal of Economics, 124(4): 1403-1448.

Imbens, Guido W. 2015. "Matching Methods in Practice: Three Examples." Journal of Human Resources, 50(2): 373-419.

Imbens, Guido W, and Jeffrey M Wooldridge. 2009. "Recent Developments in the Econometrics of Program Evaluation.” Journal of Economic Literature, 47(1): 5-86.

Koźluk, Tomasz, and Vera Zipperer. 2015. "Environmental policies and productivity growth - a critical review of empirical findings.” OECD Journal: Economic Studies, 2014: pp. 155-185.

Lutz, Benjamin Johannes. 2016. "Emissions trading and productivity: Firm-level evidence from German manufacturing." ZEW Discussion Paper.

Mackinnon, James G, and Matthew D Webb. 2019. "When and How to Deal With Clustered Errors in Regression Models." QED Working Paper.

Martin, Ralf, Laure B de Preux, and Ulrich J Wagner. 2014. "The impact of a carbon tax on manufacturing: Evidence from microdata.” Journal of Public Economics, 117: 1-14.

Mckenzie, Kenneth J. 2016. "Inside the Black Box : Marginal Effective Tax Rates in Canada - A Primer." Canadian Tax Journal, 64(4): 795-816.

McKenzie, Kenneth J., and Ergete Ferede. 2017. "The Incidence of the Corporate Income Tax on Wages: Evidence from Canadian Provinces." University of Calgary Working Paper, , (03). 
Ministry of Finance. 2008. “Budget and Fiscal Plan 2008/09-2010/11.” British Columbia.

Ministry of Finance. 2010. “Tax Schedule.” British Columbia.

Ministry of Finance. 2015. "Budget and Fiscal Plan 2015/16-2017/18.” British Columbia.

Ministry of Finance. 2017. “Budget 2017 Update 2017/18 - 2019/20.” British Columbia.

Murray, Brian, and Nicholas Rivers. 2015. "British Columbia's revenue-neutral carbon tax: A review of the latest "grand experiment" in environmental policy." Energy Policy, 86: 674-683.

Statistics Canada. 2015. "Annual Survey of Manufactures.”

Stuart, Elizabeth A., and Donald B. Rubin. 2008. "Matching With Multiple Control Groups With Adjustment for Group Differences." Journal of Educational and Behavioral Statistics, 33(3): 279-306.

Tanaka, Shinsuke, Wesley Yin, and Gary H. Jefferson. 2014. "Environmental Regulation and Industrial Performance: Evidence from China.” Working Paper.

Tombe, Trevor, and Jennifer Winter. 2015. "Environmental policy and misallocation: The productivity effect of intensity standards." Journal of Environmental Economics and Management, 72: 137-163.

Van Biesebroeck, Johannes. 2007. "Robustness of productivity estimates." Journal of Industrial Economics, 55(3): 529-569.

Yamazaki, Akio. 2017. "Jobs and climate policy: Evidence from British Columbia's revenue-neutral carbon tax." Journal of Environmental Economics and Management, 83: 197-216. 


\section{Appendices}

\section{Appendix A Model}

Here I present a more general treatment of the model shown in the text by assuming that only a portion $\lambda_{A}>0$ of the abatement investment cost is deductible. In the text, I assume that $\lambda_{A}=1$.

With $\lambda_{A}$, the profit function is expressed as follows:

$$
\pi=B(1-\sigma)^{\sigma-1} \sigma^{-\sigma}\left(1-t^{c}\right)^{-\sigma} c^{x^{1-\sigma}}-\left(1-\lambda_{A} t^{c}\right) I_{A}
$$

Solving the profit maximization problem yields:

$$
I_{A}=\Gamma^{\frac{1}{\gamma}} A^{\frac{\sigma-1}{\gamma}} \tau^{-\frac{\alpha(\sigma-1)}{\gamma}}\left(1-\lambda_{k} t^{c}\right)^{-\frac{\beta(1-\alpha)(\sigma-1)}{\gamma}}\left(1-t^{c}\right)^{\frac{1+\beta(1-\alpha)(\sigma-1)}{\gamma}}\left(1-\lambda_{A} t^{c}\right)^{\frac{-1}{\gamma}}
$$

\section{Abatement investment function}

Here I show that Eq.(A.2) is a decreasing function of carbon tax and a decreasing function of corporate income tax in more detail.

To show that Eq.(A.2) is a decreasing function of carbon tax, I take the second derivative of the profit function (Eq.(A.1)):

$$
\pi^{\prime \prime}=B(1-\sigma)^{\sigma-1} \sigma^{-\sigma}\left(1-t^{c}\right)\left(\kappa_{\alpha} A^{-1} c^{F^{1-\alpha}} \tilde{\tau}^{\alpha}\right)^{\sigma-1}(\alpha \rho(\sigma-1))(-\gamma) I_{A}^{-(\gamma+1)}
$$

In order for the second order condition of the profit maximization to be satisfied, i.e., $\pi^{\prime \prime}<0$, it must be that $\gamma>0$.

Then, notice here that the existence of $\lambda_{A}$ does not alter how the carbon tax affects the abatement investment function, i.e., the effect of the carbon tax on the abatement investment is still ambiguous as:

$$
I_{A}=\Phi \Gamma^{\frac{1}{\gamma}} \tau^{-\frac{\alpha(\sigma-1)}{\gamma}}
$$

where $\Phi$ is the rest of non-carbon tax variables and parameters in Eq.(A.2).

Next, showing that Eq.(A.2) is a decreasing function of the CIT rate is a bit more involved as $t^{c}$ shows up in multiple places. Given that $\lambda_{A} \in[0,1]$, I consider the two extreme cases, 1) $\lambda_{A}=0$, and 2) $\lambda_{A}=1$.

When $\lambda_{A}=0$,

$$
I_{A}=\Gamma^{\frac{1}{\gamma}} A^{\frac{\sigma-1}{\gamma}} \tau^{-\frac{\alpha(\sigma-1)}{\gamma}}(1+\mathrm{METR})^{-\frac{\beta(1-\alpha)(\sigma-1)}{\gamma}}\left(1-t^{c}\right)
$$


where $1+\operatorname{METR}=\frac{1-\lambda_{k} t^{c}}{1-t^{c}}$, and METR is the marginal effective tax rate. ${ }^{1}$ Eq.(A.5) is a decreasing function of the CIT as long as the METR is an increasing function of the CIT, which is true when $\lambda_{k}<1 .^{2}$

When $\lambda_{A}=1$,

$$
I_{A}=\Gamma^{\frac{1}{\gamma}} A^{\frac{\sigma-1}{\gamma}} \tau^{-\frac{\alpha(\sigma-1)}{\gamma}}(1+\mathrm{METR})^{-\frac{\beta(1-\alpha)(\sigma-1)}{\gamma}}
$$

Similarly, Eq.(A.6) is a decreasing function of the CIT as long as the METR is an increasing function of the CIT.

As I show that the abatement investment is a decreasing function of the CIT in both cases, the abatement investment is a decreasing function of the CIT regardless of the value of $\lambda_{A}$ as long as $\lambda_{k}<1$.

\section{TFP function}

Plugging Eq.(A.2) into Eq.(3.12) yields:

$$
\operatorname{TFP}=A^{1 / \gamma} \underbrace{\tilde{\Gamma} \tau^{\frac{-\alpha}{\gamma}}}_{\text {Carbon tax }} \underbrace{\left(\frac{1-t^{c}}{1-\lambda_{A} t^{c}}\right)^{\frac{\alpha \rho}{\gamma}}\left(\frac{1-\lambda_{k} t^{c}}{1-t^{c}}\right)^{-\frac{\alpha \beta(\rho(\sigma-1)-1)}{\gamma}}}_{\text {Revenue-recycling }}
$$

Here I show that the sign of carbon tax and revenue-recycling effects in Eq.(A.7).

\section{Carbon tax effect}

Similar to the abatement investment function, the sign of the carbon tax effect is ambiguous due to the presence of $\tilde{\Gamma}$ in Eq.(A.7).

\section{Revenue-recycling effect}

To determine the sign of the revenue-recycling effect, I consider the two extreme cases as before, , 1) $\lambda_{A}=0$, and 2) $\lambda_{A}=1$.

When $\lambda_{A}=0$,

$$
\mathrm{TFP}=A^{1 / \gamma} \tilde{\Gamma} \tau^{\frac{-\alpha}{\gamma}}(1+\mathrm{METR})^{\frac{\alpha \beta(1-\rho(\sigma-1))}{\gamma}}\left(1-t^{c}\right)^{\alpha \rho}
$$

Eq.(A.8) is a decreasing function of the CIT if $1 \leq \rho(\sigma-1)$. If $1>\rho(\sigma-1)$, Eq.(A.8) can still be a decreasing function of the CIT when the speed of the decrease of $\left(1-t^{c}\right)^{\alpha \rho}$ is larger than the speed of the increase of $(1+\text { METR })^{\frac{\alpha \beta(1-\rho(\sigma-1))}{\gamma}}$ with the CIT.

\footnotetext{
${ }^{1}$ See Mckenzie (2016) for a more detail explanation of the METR.
}

${ }^{2} \lambda_{k}>1$ means capital is subsidized. 
When $\lambda_{A}=1$,

$$
\mathrm{TFP}=A^{1 / \gamma} \tilde{\Gamma} \tau^{\frac{-\alpha}{\gamma}}(1+\mathrm{METR})^{\frac{\alpha \beta(1-\rho(\sigma-1))}{\gamma}}
$$

Similarly, Eq.(A.9) is a decreasing function of the CIT if $1 \leq \rho(\sigma-1)$.

In both cases, TFP is a decreasing function of the CIT if $1 \leq \rho(\sigma-1)$. This means that the reduction of the CIT will likely to have a positive impact on TFP when the abatement technology improves faster with the abatement investment, and the goods are more substitutable.

\section{Appendix B Data}

\section{B.1 The ASM-GIFI linkage}

Here I describe the detail of the linkage of two micro-data. The plant-level data used in this paper is created by merging two existing data at Statistics Canada: the Annual Survey of Manufactures (ASM) and General Index of Financial Information (GIFI). The linkage is required for estimating the production function because capital data is missing from the ASM. One issue for this linkage is that the ASM is the plant-level data while the GIFI is the firm-level data. There are three steps involved in the ASM-GIFI linkage.

First, the firm identifier is used to merge two data. One of the advantages of the ASM is that it has information about the ownership of plants. Not only does this information allow me to distinguish between singly-owned plants and multi-plant firms, but also it enables the match of firms between these two data. The data is merged at the firm-level. Next two steps disaggregate this firm-level data from the GIFI to the plant-level.

Next step is to determine what percentage of the firm's business activities comes from the manufacturing. This is important as some firms may be involved in various activities including non-manufacturing. I calculated the share of revenues coming strictly from manufacturing. I divided the manufacturing revenues by the total revenues. I use this share to split the firm's capital into manufacturing and non-manufacturing capitals.

The last step is to allocate the firm's manufacturing capital to its plants. ${ }^{3}$ To do this, I calculated the share of revenues for each plant relative to manufacturing revenues of its parent firm. I used this share to allocate the firm-level capital down to each plant within the firm.

\section{B.2 Similarity of tax-paying and in-loss plants in BC}

In this appendix, I explore a concern that tax-paying and in-loss plants may operate differently. I do this in two ways. First, I compare plant characteristics between these two groups. Second, I

\footnotetext{
${ }^{3}$ This step is irrelevant for singly-owned firms as there is only one plant for these firms.
} 
Table B.1: Comparison of Plant Characteristics Between Tax-paying and In-loss Plants

\begin{tabular}{|c|c|c|c|c|}
\hline & In-loss & Tax-paying & Difference & $\begin{array}{c}\text { Standardized } \\
\text { Difference }\end{array}$ \\
\hline \multirow[t]{2}{*}{ Output } & 14.25 & 14.71 & $-0.465 * * *$ & \\
\hline & $(1.749)$ & $(1.542)$ & $(0.0313)$ & 0.282 \\
\hline \multirow[t]{2}{*}{ Value-added } & 13.49 & 14.01 & $-0.520 * * *$ & \\
\hline & $(1.731)$ & $(1.487)$ & $(0.0308)$ & 0.322 \\
\hline \multirow[t]{2}{*}{ Labor } & 2.461 & 2.691 & $-0.229 * * *$ & \\
\hline & $(1.322)$ & $(1.277)$ & $(0.0242)$ & 0.176 \\
\hline \multirow[t]{2}{*}{ Capital } & 9.609 & 12.42 & $-2.810 * * *$ & \\
\hline & $(7.638)$ & $(3.817)$ & $(0.127)$ & 0.465 \\
\hline \multirow[t]{2}{*}{ Intermediate } & 13.53 & 13.94 & $-0.413 * * *$ & \\
\hline & $(1.926)$ & $(1.731)$ & $(0.0346)$ & 0.226 \\
\hline \multirow[t]{2}{*}{ Material } & 13.46 & 13.88 & $-0.415 * * *$ & \\
\hline & $(1.935)$ & $(1.785)$ & $(0.0350)$ & 0.223 \\
\hline \multirow[t]{2}{*}{ Energy } & 10.12 & 10.48 & $-0.356 * * *$ & \\
\hline & $(2.632)$ & $(2.315)$ & $(0.0471)$ & 0.144 \\
\hline \multirow[t]{2}{*}{ Energy intensity } & 0.0362 & 0.0285 & $0.00773 * *$ & \\
\hline & $(0.145)$ & $(0.0863)$ & $(0.00244)$ & -0.065 \\
\hline \multirow[t]{2}{*}{ Fuel } & 9.084 & 9.479 & $-0.395 * * *$ & \\
\hline & $(3.441)$ & (3.249) & $(0.0625)$ & 0.118 \\
\hline \multirow[t]{2}{*}{ \# of plants per firm } & 1.459 & 3.346 & $-1.887 * * *$ & \\
\hline & $(2.377)$ & $(12.82)$ & $(0.125)$ & 0.205 \\
\hline \multirow[t]{2}{*}{ Age } & 5.194 & 5.731 & $-0.536 * * *$ & \\
\hline & $(2.122)$ & $(1.852)$ & $(0.0379)$ & 0.269 \\
\hline \multirow[t]{2}{*}{ Int'l export share } & 0.247 & 0.227 & $0.0198 * *$ & \\
\hline & $(0.339)$ & $(0.320)$ & $(0.00616)$ & -0.060 \\
\hline \multirow[t]{2}{*}{ Inter-provincial export share } & 0.117 & 0.135 & $-0.0181 * * *$ & \\
\hline & $(0.199)$ & $(0.219)$ & $(0.00376)$ & 0.086 \\
\hline \multirow[t]{2}{*}{ Total export share } & 0.364 & 0.362 & 0.00172 & \\
\hline & $(0.390)$ & $(0.381)$ & $(0.00715)$ & -0.004 \\
\hline \multirow[t]{2}{*}{ Share of exporting plants } & 0.632 & 0.677 & $-0.0447 * * *$ & \\
\hline & $(0.482)$ & $(0.468)$ & $(0.00882)$ & 0.094 \\
\hline \multirow[t]{2}{*}{ Share of plants with R\&D } & 0.709 & 0.673 & $0.0357 * * *$ & \\
\hline & $(0.454)$ & $(0.469)$ & $(0.00844)$ & -0.077 \\
\hline
\end{tabular}

Notes: This table presents the pre-policy mean of various plant characteristics for in-loss and tax-paying plants in British Columbia. $T$-tests are performed to exam whether the pre-policy mean differences are different from zero between these two groups. Standardized differences are calculated as $\frac{\bar{Y}_{\text {treated }}-\bar{Y}_{\text {control }}}{\sqrt{\left(s_{\text {treated }}^{2}+s_{\text {control }}^{2}\right) / 2}}$, and correct the $t$-statistics of the $t$-test for the sample size. *** Significant at the 1 percent level, ${ }^{* *}$ Significant at the 5 percent level, ${ }^{*}$ Significant at the 10 percent level.

check to see whether the pre-policy productivity trends for these two groups are parallel.

The first important fact about in-loss plants in the data is that they are, in fact, operating. Table B.B. 2 shows that the mean differences of these important plant characteristics are statistically different from zero between these groups using the $t$-tests. However, most of the standardized differences of these variables are not larger than 0.25 . These suggest that in-loss plants are operating 


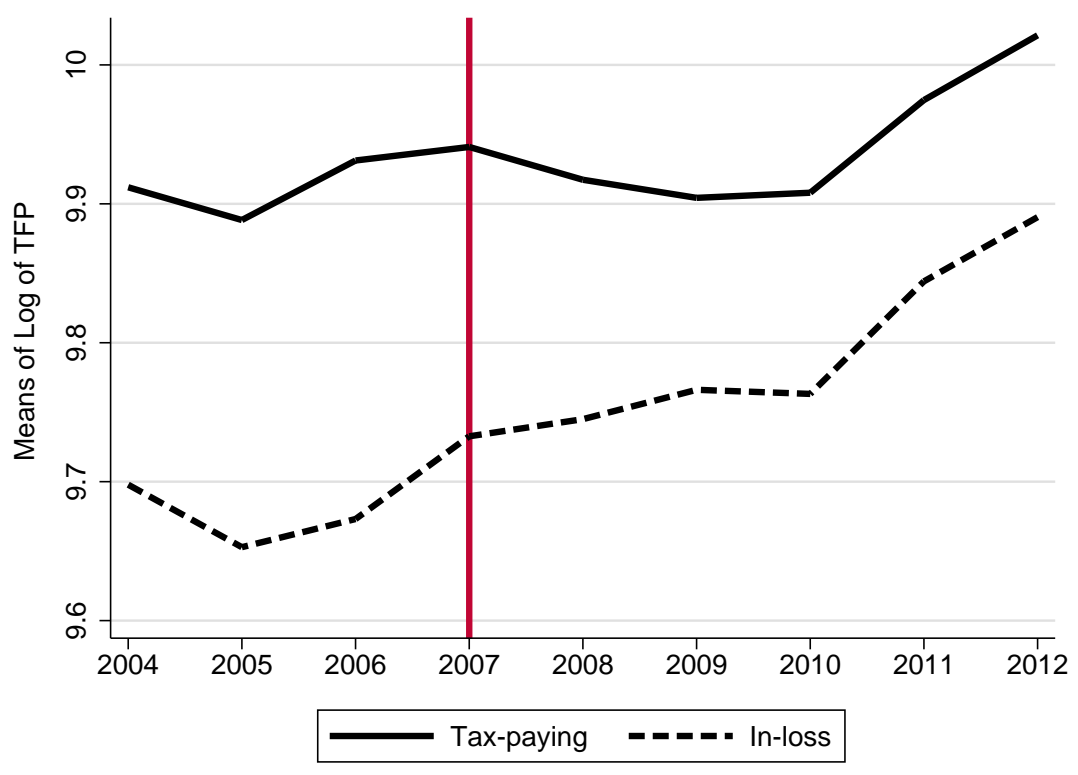

Figure B.1: Trends of TFP

Note: This figure plots the trends of TFP for tax-paying plants and in-loss plants in BC.

Source: Author's calculation.

in a similar fashion so that they are a good candidate to be treated as counterfactual for tax-paying plants to identify the revenue-recycling effect of the policy.

Furthermore, to credibly identify the revenue-recycling effect of the policy, the pre-policy productivity trends should be parallel between tax-paying and in-loss plants in BC. Figure B.1 shows the trends of productivity for tax-paying and in-loss plants in $\mathrm{BC}$ are reasonably parallel during the pre-policy period. This further justifies the use of in-loss plants as a control group.

\section{B.3 Balancing with the propensity score weights}

Here I discuss the use of the propensity scores in the estimation. One advantage of the data used in this paper is the detailed coverage of the plants' information. To take advantage of this rich data, I augment the conventional difference-in-differences estimator with weights based on propensity scores. More weights are given to control plants that resemble treated plants. This method re-weights the distribution of control plants based on the propensity scores, which allows me to compare similar treated and control plants. Table B.2 lists a full set of variables used for estimating the propensity scores.

To illustrate the effectiveness of the propensity score re-weighting, I show how similar plants in $\mathrm{BC}$ and plants in ROC are in terms of their plant characteristics. Table B.3 shows the difference in means for various plant characteristics between BC and ROC plants from the pre-policy period. I 
Table B.2: A full set of variables used for estimating the propensity scores

\begin{tabular}{ll}
\hline \hline TFP & Taxable income \\
Output & Labor \\
Capital & Intermediates \\
Production workers & International export \\
Non-production workers & Intra-provincial export \\
R\&D & Wage for production worker \\
Wage & Salaries for non-production worker \\
Utility bill & Electricity \\
International export intensity & Gasoline \\
Intra-provincial export intensity & Diesel fuel \\
4 digit NAICS ID & Natural gas \\
Plant age & Coal \\
Total expenditure & Light fuel oil \\
Revenue & Heavy fuel oil \\
Profits & Liquefied petroleum gases \\
\# of subsidiary & Others energy \\
\hline \hline
\end{tabular}

Note: All energy related variables are in expenditures, not in quantities.

use the standardized differences to examine whether the differences are statistically different from zero.

A clear pattern emerged from this comparison. The mean differences of plant characteristics between BC and ROC plants shrink substantially when using the weights. Comparing the size of the standardized differences also reinforces this as they also become smaller and far less than 0.25. 
Table B.3: Comparing plant characteristics between BC and ROC plants with and without the weights

\begin{tabular}{lcccc}
\hline \hline & \multicolumn{2}{c}{ Unweighted } & \multicolumn{2}{c}{ Weighted } \\
\cline { 2 - 5 } & Difference & $\begin{array}{c}\text { Standardized } \\
\text { Difference }\end{array}$ & Difference & $\begin{array}{c}\text { Standardized } \\
\text { Difference }\end{array}$ \\
\hline Output & -0.420 & -0.262 & -0.097 & -0.059 \\
Value-added & -0.365 & -0.232 & -0.076 & -0.047 \\
Labor & -0.328 & -0.246 & -0.076 & -0.057 \\
Capital & -0.382 & -0.073 & -0.117 & -0.022 \\
Intermediate & -0.470 & -0.263 & -0.106 & -0.058 \\
Material & -0.468 & -0.256 & -0.104 & -0.055 \\
Energy & -0.541 & -0.231 & -0.137 & -0.057 \\
Energy intensity & -0.007 & -0.041 & -0.006 & -0.036 \\
Fuel & -0.432 & -0.132 & -0.076 & -0.023 \\
\# of plants per firm & -0.966 & -0.075 & -0.395 & -0.033 \\
Age & -0.066 & -0.035 & -0.029 & -0.015 \\
Int'l export share & 0.017 & 0.054 & 0.011 & 0.034 \\
Inter-provincial export share & -0.024 & -0.106 & -0.011 & -0.048 \\
Total export share & -0.007 & -0.018 & 0.000 & 0.001 \\
Share of exporting plants & -0.038 & -0.083 & -0.008 & -0.018 \\
Share of plants with R\&D & 0.021 & 0.044 & 0.008 & 0.018 \\
\hline \hline
\end{tabular}

Note: This table shows the difference in means of plant characteristics between BC and ROC plants from the pre-policy period (2004-2007). Unweighted indicates that the propensity scores (PS) were not used to calculate the mean differences while Weighted indicates that the PS were used. Standardized differences (SD) are calculated as $\frac{\bar{Y}_{\text {treated }}-\bar{Y}_{\text {control }}}{\sqrt{\left(s_{\text {treated }}^{2}+s_{\text {control }}^{2}\right) / 2}}$, and correct the $t$-statistics of the $t$-test for the sample size. SD being larger than 0.25 means that the difference is statistically different from zero.

\section{Appendix C Additional Results}

In this appendix, I present additional results discussed in the main texts.

\section{C.1 Testing the pre-treatment effects}

To strengthen the credibility of the identification of the treatment effects, I examine whether the carbon tax and revenue-recycling effects are statistically significant during the pre-policy period. This is often referred to as a placebo test, treating the pre-policy period to be treated. I present the result of the two specifications in Table C.1. In column 1, I estimate Eq.(4.1) using the data only from the pre-policy period (2004-2007). In column 2, I interact both carbon tax and revenuerecycling effects with year dummies. In both cases, the results show that the carbon tax and 
Table C.1: Testing the Pre-treatment Effects

\begin{tabular}{|c|c|c|}
\hline & (1) & $(2)$ \\
\hline $\mathrm{CTax}_{i p t}$ & $\begin{array}{c}0.246 \\
(0.228)\end{array}$ & \\
\hline$\times$ year 2004 & & $\begin{array}{c}0.278 \\
(0.226)\end{array}$ \\
\hline$\times$ year 2005 & & $\begin{array}{c}0.256 \\
(0.223)\end{array}$ \\
\hline$\times$ year 2006 & & $\begin{array}{c}0.203 \\
(0.223)\end{array}$ \\
\hline$\times$ year $_{2007}$ & & $\begin{array}{c}0.204 \\
(0.222)\end{array}$ \\
\hline $\operatorname{Recycling}_{i p t}$ & $\begin{array}{c}0.0182 \\
(0.0332)\end{array}$ & \\
\hline$\times$ year 2004 & & $\begin{array}{c}0.0267 \\
(0.0424)\end{array}$ \\
\hline$\times$ year 2005 & & $\begin{array}{c}0.0239 \\
(0.0387)\end{array}$ \\
\hline$\times$ year2006 & & $\begin{array}{c}0.0902 * * \\
(0.0359)\end{array}$ \\
\hline$\times$ year $_{2007}$ & & $\begin{array}{c}0.0920 * * \\
(0.0361)\end{array}$ \\
\hline$N$ & 120433 & 120433 \\
\hline$R^{2}$ & 0.740 & 0.725 \\
\hline
\end{tabular}

Notes: These estimates only use data from the pre-policy period (2004-2007). Treatment variables, CTax $i p t$ and Recycling $i p t$, are defined as in Eq.(4.1). Column (2) interacts treatment variables with year dummies. Both specifications include plant FE and provincial GDP as a control. Column (1) also includes industry (4-digit NAICS) by year FE. To account for serial correlations and within sub-industry correlations, standard errors are clustered by province, reported in parentheses. ${ }^{* * *}$ Significant at the 1 percent level, ${ }^{* *}$ Significant at the 5 percent level, ${ }^{*}$ Significant at the 10 percent level.

revenue-recycling effects are not statistically significant.

\section{C.2 Robustness of revenue-recycling effect}

In Eq.(4.1), the revenue-recycling effect is defined as $\mathbb{1}\left(\mathrm{TI}_{i}>0\right) \times\left(1-\mathrm{CIT}_{p t}\right)$ where $\mathbb{1}\left(\mathrm{TI}_{i}>\right.$ $0)$ is an indicator function that takes one when average taxable corporate income during the prepolicy period is strictly positive, and $\left(1-\mathrm{CIT}_{p t}\right)$ is the net of BC's corporate income tax rate. Here I test the robustness of the estimates using different thresholds for the taxable income indicator function. 
Table C.2: Checking Robustness of Revenue-recycling effect

\begin{tabular}{lccc}
\hline \hline & $(1)$ & $(2)$ & $(3)$ \\
\hline CTax $_{i p t}$ & $-7.35^{* * *}$ & $-7.35^{* * *}$ & $-7.35^{* * *}$ \\
& $(1.30)$ & $(1.299)$ & $(1.298)$ \\
Recycling $_{i p t}\left(\mathrm{TI}_{i}>0\right)$ & $0.13^{*}$ & & \\
& $(0.07)$ & & \\
Recycling $_{i p t}\left(\mathrm{TI}_{i}>\$ 230\right)$ & & $0.131^{* *}$ & \\
& & $(0.062)$ & \\
Recycling $_{i p t}\left(\mathrm{TI}_{i}>\$ 1,679\right)$ & & & $0.133^{* *}$ \\
& & & $(0.062)$ \\
$N$ & & & \\
$\mathrm{R}^{2}$ & 237,333 & 237,333 & 237,333 \\
\hline \hline
\end{tabular}

Notes: Dependent variable and $\mathrm{CTax}_{i p t}$ are defined as Eq.(4.1). The definition of Recycling $_{i p t}$ is altered, and its result is presented in each column. Column 1 is taken from column 6 of Table 2. In column 2, I changed the threshold for Recycling $i p t$ from zero to approximately $\$ 230$, which is the 1st percentile of plants whose taxable income is positive. I further change the threshold of Recycling ${ }_{i p t}$ in column 3 to $\$ 1,679$ (5th percentile). All specifications includes plant FE, industry (4-digit NAICS) by time FE, and provincial GDP as a control. To account for serial correlations and within sub-industry correlations, standard errors are clustered by province, reported in parentheses.

*** Significant at the 1 percent level, ${ }^{* *}$ Significant at the 5 percent level, ${ }^{*}$ Significant at the 10 percent level.

Table C.2 presents the results of two specifications along with the base result, which is taken from column 6 of Table 2. In column 2 of Table C.2, I changed the threshold to be less than $5^{\text {th }}$ percentile of taxable income (\$230) among plants with average positive income during the pre-policy period. In column 3, I changed the threshold to be less than $10^{\text {th }}$ percentile $(\$ 1,679)$. Regardless of the different thresholds, I find robust evidence that the revenue-recycling effect of the carbon tax is statistically significant and positive. 


\section{Appendix D For Online Publication}

\section{D.1 Construction of Total Factor Productivity}

In this appendix, I describe the details of the data and method used for the construction of the total factor productivity and its method. First, I explain the data below.

To estimate plant-level total factor productivity, two confidential micro-level data are merged, the Annual Survey of Manufactures (ASM) and General Index of Financial Information (GIFI). The ASM is an annual survey that contains information on manufacturing activities for all manufacturing locations in Canada. The GIFI is an extensive list of financial statement items, which businesses use to file their T2 corporate income tax return.

\section{Annual Survey of Manufactures}

Output $\left(Y_{i t}\right)$ : Plant output is total value of shipments of manufacturing goods minus raw material expenditure. It is deflated to 2007 dollars using industry-specific price indexes from the Canadian Productivity Accounts.

Labor $\left(L_{i t}\right)$ : I use the number of total employees, which are the sum of production workers and non-production workers.

Energy $\left(E_{i t}\right)$ : Energy is total of energy expenditures.

\section{General Index of Financial Information}

Capital $\left(K_{i t}\right)$ : Capital is the book values of tangible assets, deflated to 2007 dollars using industryspecific price indexes from the Canadian Productivity Accounts.

Total Factor Productivity: Plant-level TFP is the log residual from a semiparametric production function estimation. I explain the details of the method below. ${ }^{4}$

Consider a plant with a Cobb-Douglas value-added production function: ${ }^{5}$

$$
Y_{i t}=A_{i t} L_{i t}^{\beta_{l}} K_{i t}^{\beta_{k}} E_{i t}^{\beta_{e}}
$$

Taking logs yields:

$$
y_{i t}=\beta_{0}+\beta_{l} l_{i t}+\beta_{k} k_{i t}+\beta_{e} e_{i t}+\epsilon_{i t}
$$

\footnotetext{
${ }^{4}$ Although I explain each step of the modified ACF method one by one here, I used the user-written package, prodest, available in stata to implement these procedures. I am grateful for the creators of the package, Gabriele Rovigatti and Vincenzo Mollisi, for their help in modifying the ACF method using their package.

${ }^{5} \mathrm{I}$ implicitly assume that a gross output production function is Leontief in the raw materials, i.e., $G O=$ $G(F(K, L, E), M)$.
} 
where lowercase symbols represent the $\operatorname{logs}$ of variables and $\ln \left(A_{i t}\right)=\beta_{0}+\epsilon_{i t}$. To estimate the production function using the algorithm introduced by Ackerberg, Caves and Frazer (2015) henceforth ACF method, $\epsilon_{i t}$ is separated into two components, $\omega_{i t}$ and $\eta_{i t}$.

$$
y_{i t}=\beta_{0}+\beta_{l} l_{i t}+\beta_{k} k_{i t}+\beta_{e} e_{i t}+\omega_{i t}+\eta_{i t}
$$

where $\omega_{i t}$ is the unobserved productivity and $\eta_{i t}$ is the idiosyncratic error term. This method assumes each input is determined at a different time. Capital is determined at $t-1$ while labor and energy are determined at $t-b$ where $b \in(0,1)$. These differences in decision timing are what make the identification of the input coefficients possible. Now raw material input $\left(M_{i t}\right)$ is used as a proxy to express the unobserved productivity with observables. Unlike the rest of variables, raw material is determined at $t$. Assume that:

$$
m_{i t}=m_{i t}\left(\omega_{i t}, l_{i t}, k_{i t}, e_{i t}, z_{i t}\right)
$$

While the original ACF method assumes that $m_{i t}$ depends only on the unobserved productivity, capital, and labor, this formulation is problematic when the objective is to estimate the productivity effect of environmental regulations. This is because there could be a selection bias arising from only productive plants engaging in the energy-saving activities. There could also be another simultaneity bias because the energy-saving decisions depends on a prior expectation of its own productivity. To address this issue, the vector of the determinants of productivity, $z_{i t}$, is included in $m_{i t}$. Following De Loecker (2013) and Lutz (2016), $\boldsymbol{z}_{i t}$ consists of export status, R\&D status, energy intensity, and carbon tax dummy.

By assuming that $m_{i t}$ is strictly positive and monotonic in $\omega_{i t}, m_{i t}$ can be inverted to express the unobserved productivity as a function of observables:

$$
\omega_{i t}=h_{t}\left(l_{i t}, k_{i t}, e_{i t}, m_{i t}, z_{i t}\right)
$$

Then, substituting Eq.(D.5) into Eq.(D.3) yields:

$$
y_{i t}=\beta_{0}+\beta_{l} l_{i t}+\beta_{k} k_{i t}+\beta_{e} e_{i t}+h_{t}\left(l_{i t}, k_{i t}, e_{i t}, m_{i t}, z_{i t}\right)+\eta_{i t}
$$

The first stage of ACF method involves estimating Eq.(D.6) using a semi-parametric method, treating $h_{t}\left(l_{i t}, k_{i t}, e_{i t}, m_{i t}, z_{i t}\right)$ non-parametrically. A (4th-order) polynomial function, $\phi_{t}($.$) , in all its$ variables is often imposed as:

$$
y_{i t}=\phi_{t}\left(l_{i t}, k_{i t}, e_{i t}, m_{i t}, z_{i t}\right)+\eta_{i t}
$$


Although estimating Eq.(D.7) does not identify any input coefficients, it is still important as it nets out $\eta_{i t}$ and yields $\widehat{\phi}_{t}$, which is used in the second stage.

Here I assume that the unobserved productivity follows the first-order Markov process:

$$
\begin{aligned}
\omega_{i t} & =E\left[\omega_{i t} \mid \boldsymbol{J}_{i t-1}\right]+\xi_{i t} \\
& =E\left[\omega_{i t} \mid \omega_{i t-1}, z_{i t-1}\right]+\xi_{i t} \\
& =g\left(\omega_{i t-1}, z_{i t-1}\right)+\xi_{i t}
\end{aligned}
$$

where $\boldsymbol{J}_{\boldsymbol{i t - 1} \mathbf{1}}$ is the information set at time $t-1$. From the first stage, I have:

$$
\widehat{\omega}_{i t-1}=\widehat{\phi}_{i t-1}-\beta_{l} l_{i t-1}-\beta_{k} k_{i t-1}-\beta_{e} e_{i t-1}
$$

Substituting Eq.(D.10) and Eq.(D.11) into Eq.(D.3) yields:

$$
\begin{aligned}
y_{i t}= & \beta_{0}+\beta_{l} l_{i t}+\beta_{k} k_{i t}+\beta_{e} e_{i t} \\
& +g^{\prime}\left(\widehat{\phi}_{i t-1}-\beta_{l} l_{i t-1}-\beta_{k} k_{i t-1}-\beta_{e} e_{i t-1}, z_{i t-1}\right)+\xi_{i t}+\eta_{i t}
\end{aligned}
$$

Then three moment conditions are used to identify $\beta_{l}, \beta_{k}$, and $\beta_{e}$.

$$
\begin{aligned}
E\left(\xi_{i t}+\eta_{i t}, k_{i t}\right) & =0 \\
E\left(\xi_{i t}+\eta_{i t}, l_{i t-1}\right) & =0 \\
E\left(\xi_{i t}+\eta_{i t}, e_{i t-1}\right) & =0
\end{aligned}
$$

Finally, with the unbiased and consistent estimate of all input coefficients, $\widehat{\beta}_{l}, \widehat{\beta}_{k}, \widehat{\beta}_{e}$, plant-level TFP is calculated as a residual:

$$
\operatorname{tfp}=y_{i t}-\widehat{\beta}_{0}-\widehat{\beta}_{l} l_{i t}-\widehat{\beta}_{k} k_{i t}-\widehat{\beta}_{e} e_{i t}
$$

I estimate Eq.(D.16) for each of 21 sub-sectors (at 3-digit NAICS) within manufacturing industry separately.

\section{D.2 Constructing the quantity-based TFP (TFPQ)}

In this appendix, I summarize how I construct the quantity-based TFP (TFPQ) using the approach proposed by Hsieh and Klenow (2009). This approach derives an expression for TFPQ from the revenue-based TFP (TFPR) without needing to obtain the plant-specific output prices.

The basic model is based on a standard model of monopolistic competition with heterogeneous 
plants. Single final good $Y$ is produced by a representative firm in a perfect competitive final output market with Cobb-Douglas production technology:

$$
Y=\prod_{s=1}^{S} Y_{s}^{\theta_{s}}, \quad \sum_{s=1}^{S} \theta_{s}=1
$$

The final good producer maximizes:

$$
\max _{Y_{s}} \quad P Y-\sum_{s=1}^{S} P_{s} Y_{s}=P \prod_{s=1}^{S} Y_{s}^{\theta_{s}}-\sum_{s=1}^{S} P_{S} Y_{S}
$$

and the first-order condition (FOC) is:

$$
\frac{\theta_{s}}{Y_{s}} P \prod_{s=1}^{S} Y_{s}^{\theta_{s}}=P_{s} \quad \Rightarrow \quad P_{s} Y_{s}=\theta_{s} P Y
$$

Industry output $Y_{S}$ is itself a CES aggregate of $M_{S}$ differentiated products:

$$
Y_{s}=\left[\sum_{M_{s}} Y_{s i}^{\frac{\sigma-1}{\sigma}}\right]^{\frac{\sigma}{\sigma-1}}
$$

The demand for these industries is given by maximizing:

$$
\max _{Y_{s i}} \quad P_{S} Y_{s}-\sum_{M_{s}} P_{s i} Y_{s i}=P_{S}\left[\sum_{M_{s}} Y_{s i}^{\frac{\sigma-1}{\sigma}}\right]^{\frac{\sigma}{\sigma-1}}-\sum_{M_{s}} P_{s i} Y_{s i}
$$

and the FOC is:

$$
\begin{aligned}
P_{s i} & =\frac{\sigma}{\sigma-1} P_{s}\left[\sum_{M_{s}} Y_{s i}^{\frac{\sigma-1}{\sigma}}\right]^{\frac{1}{\sigma-1}} \frac{\sigma-1}{\sigma} Y_{s i}^{\frac{-1}{\sigma}} \\
& =P_{s} Y_{s}^{\frac{1}{\sigma}} Y_{s i}^{\frac{-1}{\sigma}}
\end{aligned}
$$

Then, multiple both sides by $Y_{s i}$ yields:

$$
P_{s i} Y_{s i}=P_{s} Y_{s}^{\frac{1}{\sigma}} Y_{s i}^{\frac{\sigma-1}{\sigma}}
$$


Then, raise both sides by $\sigma /(\sigma-1)$ yields:

$$
Y_{s i}=\left(P_{s} Y_{s}^{\frac{1}{\sigma}}\right)^{\frac{-\sigma}{\sigma-1}}\left(P_{s i} Y_{s i}\right)^{\frac{\sigma}{\sigma-1}}
$$

Finally, Foster, Haltiwanger and Syverson (2008) defines TFPQ as:

$$
T F P Q_{s i} \equiv A_{s i}=\frac{Y_{s i}}{K_{s i}^{\alpha_{s}} L_{s i}^{1-\alpha_{s i}}}
$$

Although we do not have neither $P_{s i}$ nor $Y_{s i}$ directly from the data, using (D.25) (i.e., expressing $Y_{s i}$ as a function of $\left.P_{s i} Y_{s i}\right)$ helps me derive the following:

$$
A_{s i}=\kappa_{s} \frac{\left(P_{s i} Y_{s i}\right)^{\frac{\sigma}{\sigma-1}}}{K_{s i}^{\alpha_{s}} L_{s i}^{1-\alpha_{s i}}}
$$

where $\kappa_{S}=\left(P_{S} Y_{S}\right)^{-\frac{1}{\sigma-1}} / P_{S}$. Then,

$$
\ln A_{s i}=\ln \kappa_{s}+\frac{\sigma}{\sigma-1} \ln P_{s i} Y_{s i}-\alpha_{s} k_{s i}-\left(1-\alpha_{s}\right) l_{s i}
$$

This equation requires only an assumption about the elasticity of substitution between plant value-added, $\sigma$. It requires neither the plant-level output price nor the plant-level output. Following Hsieh and Klenow (2009), I set $\sigma=3$ as estimates of the substitutability of competing manufacturers in the trade and industrial organization literature typically range from 3 to 10 . In estimating TFPQ, I ignore the industry-common term, $\kappa$, because this does not vary across plants within the same sub-industry, which would be captured by the fixed effects. Given that I estimate TFPQ for each sub-industry separately, this term does not affect the plant-level TFPQ within the same sub-industry. With $\sigma=3$, estimating TFPQ is as simple as scaling down the revenue-based value-added by $2 / 3$ and re-run the Ackerberg, Caves and Frazer algorithm.

\section{D.3 Additional Results}

\section{D.3.1 Additional Robustness Check by Placebo Tests}

In Appendix C.C.1, I performed a placebo test using the data only from the pre-policy period. Alternatively, one can also perform a placebo test using control groups to be treated. This allows me to test whether the policy also affected other provinces, often called contamination or spillover effect. If so, this violates an important assumption called the stable unit treatment value assumption (SUTVA) required for identification. Here I test the validity of the SUTVA. 
Table D.1: Placebo Tests by Implementing Fake Carbon Tax in Other Provinces

\begin{tabular}{lccccccc}
\hline \hline & $(1)$ & $(2)$ & $(3)$ & $(4)$ & $(5)$ & $(6)$ & $(7)$ \\
& $\mathrm{AB}$ & $\mathrm{NS}$ & $\mathrm{NB}$ & $\mathrm{QC}$ & $\mathrm{ON}$ & $\mathrm{MB}$ & $\mathrm{SK}$ \\
\hline CTax & $-0.0507 * * *$ & $12.22 *$ & -1.204 & 2.629 & $1.479 * *$ & 6.703 & 3.069 \\
& $(0.0107)$ & $(6.227)$ & $(2.305)$ & $(2.085)$ & $(0.632)$ & $(7.327)$ & $(2.663)$ \\
Recycling & -0.00427 & 0.249 & 0.121 & 0.0332 & 0.0694 & 0.181 & 0.110 \\
& $(0.137)$ & $(0.227)$ & $(0.107)$ & $(0.0436)$ & $(0.0528)$ & $(0.114)$ & $(0.143)$ \\
$N$ & & & & & & & \\
$R^{2}$ & 206,760 & 206,765 & 206,774 & 206,772 & 206,775 & 206,766 & 206,775 \\
\hline \hline
\end{tabular}

Notes: Provincial abbreviation is as follows: Alberta (AB), Nova Scotia (NS), New Brunswick (NB), Québec (QC), Ontario (ON), Manitoba (MB), and Saskatchewan(SK). All specifications includes plant FE, industry (3-digit NAICS) by time FE, and provincial GDP as a control. To account for serial correlations and within sub-industry correlations, standard errors are clustered by 3-digit NAICS industry $\times$ province, reported in parentheses.

*** Significant at the 1 percent level, ** Significant at the 5 percent level, * Significant at the 10 percent level.

Similar to performing the placebo test only using the pre-policy period, I impose a "placebo" carbon tax and "placebo" revenue-recycling effects on other provinces. If there are no spillover effects, these "placebo" effects should not have any productivity effects. ${ }^{6}$

The results are reported in Table D.1. Each column reports the results of estimation for each province. First finding worth noting is that there is no province with both carbon tax and revenuerecycling effects statistically significant. The carbon tax effect is statistically significant for Alberta, Nova Scotia, and Ontario although the signs are reversed for Nova Scotia and Ontario. The revenue-recycling effect is not statistically significant for all provinces. These results suggest that the identification in the main text is not biased by the spillover effects, which validates the SUTVA in this content.

\footnotetext{
${ }^{6}$ This version of a placebo test is conducted using multiple control groups (non-BC provinces), and treating one of them as a pseudo treatment group. See Imbens and Wooldridge (2009) for more details.
} 